\title{
DNMT1 is predictive of survival and associated with Ki-67 expression in R-CHOP-treated diffuse large B-cell lymphomas
}

Suet Kee Loo ${ }^{1}$, Ewe Seng Ch'ng' ${ }^{2}$, Charles H. Lawrie ${ }^{3,4}$, María Arestin Muruzabal ${ }^{4}$, Ayman Gaafar $^{5}$, María Puente Pomposo 6 , Azlan Husin ${ }^{7}$, Md. Salzihan Md. Salleh ${ }^{8}$, Alison H. Banham³, Lars M. Pedersen ${ }^{9}$, Michael B. Møller ${ }^{10}$, Tina M. Green ${ }^{10}$, Kah Keng Wong ${ }^{1}$

1Department of Immunology, School of Medical Sciences, Universiti Sains Malaysia, 16150 Kelantan, Malaysia.

${ }^{2}$ Advanced Medical and Dental Institute, Universiti Sains Malaysia, Bertam, 13200 Kepala Batas, Pulau Pinang, Malaysia.

${ }^{3}$ Nuffield Division of Clinical Laboratory Sciences, Radcliffe Department of Medicine, University of Oxford, John Radcliffe Hospital, Oxford OX3 9DU, United Kingdom.

${ }^{4}$ Oncology Department, Biodonostia Research Institute, San Sebastian, 20014, Spain.

${ }^{5}$ Department of Pathology, Hospital Universitario Cruces, Barakaldo, Spain.

${ }^{6}$ Department of Hematology, Hospital Universitario Cruces, Barakaldo, Spain.

${ }^{7}$ Department of Medicine, School of Medical Sciences, Universiti Sains Malaysia, 16150

Kelantan, Malaysia.

${ }^{8}$ Department of Pathology, School of Medical Sciences, Universiti Sains Malaysia, 16150

Kelantan, Malaysia.

${ }^{9}$ Department of Haematology, Herlev University Hospital, Copenhagen, Denmark.

${ }^{10}$ Department of Pathology, Odense University Hospital, Odense, Denmark.

Running head: DNMT1 Expression and Prognosis in DLBCL

\section{Corresponding author}

Dr. Kah Keng Wong (BSc Hons, Mal; DPhil, Oxon)

Department of Immunology, School of Medical Sciences, Health Campus, Universiti Sains Malaysia, 16150 Kubang Kerian, Kelantan, Malaysia E-mail: kahkeng@usm.my ; Tel: +609 7676229 ; Fax: +609 7653370

Word count for abstract: 144; Word count for main texts: 3,092; Number of figures: 4; Number of tables: 2; Number of supplementary table: 1 ; Number of supplementary figures: 4 


\section{ABSTRACT}

DNMT1 is a target of approved anti-cancer drugs including decitabine. However, the prognostic value of DNMT1 protein expression in R-CHOP-treated diffuse large B-cell lymphomas (DLBCLs) remains unexplored. Here we showed that DNMT1 was expressed in majority of DLBCL cases (n=209/230; 90.9\%) with higher expression in GC B-cell-like (GCB)-DLBCL subtype. Low and negative DNMT1 expression (20\% cut-off; $n=33 / 230 ; 14.3 \%)$ was predictive of worse overall survival (OS; $P<0.001)$ and progression-free survival (PFS; $P<0.001)$. Nonetheless, of the 209 DNMT1-positive patients, 33\% and 42\% did not achieve 5-year OS and PFS, respectively, indicating that DNMT1-positive patients showed considerably heterogeneous outcomes. Moreover, DNMT1 was frequently expressed in mitotic cells and significantly correlated with Ki-67 or BCL6 expression ( $r=0.60$ or 0.44 , respectively; $P<0.001$ ). We demonstrate that DNMT1 is predictive of DLBCL patients' survival, and suggest that DNMT1 could be a DLBCL therapeutic target due to its significant association with Ki-67.

Keywords: Diffuse large B-cell lymphoma, DNMT1, survival, Ki-67, BCL6 


\subsection{INTRODUCTION}

Diffuse large B-cell lymphoma (DLBCL) is an aggressive subtype of mature B-cell neoplasm ${ }^{1}$ where approximately $30-40 \%$ of the patients develop relapsed/refractory disease despite the use of the standard immunochemotherapy regimen R-CHOP (rituximab, cyclophosphamide, doxorubicin, vincristine, and prednisone). ${ }^{2}$ Gene expression profiling (GEP) has identified at least two clinically and biologically distinct DLBCL subtypes: germinal center (GC) B-cell-like DLBCL (GCB-DLBCL) and activated B-cell-like DLBCL (ABC-DLBCL) subtypes, ${ }^{3}$ with ABCDLBCL patients exhibiting worse outcomes in response to the $\mathrm{R}-\mathrm{CHOP}$ regimen. ${ }^{4,5}$

Altered epigenetic regulation including methylation profiles is a recognized feature of DLBCL. ${ }^{6}$ Molecular subtypes of DLBCL (ABC- or GCB-DLBCL) exhibit distinct DNA methylation profiles, ${ }^{7}$ and greater magnitude of DNA methylation changes from normal GC B cells is associated with worse outcomes in R-CHOP-treated DLBCL patients. ${ }^{8}$ DNA methylation of gene promoters at CpG sites and intragenic regions is mediated by DNA methyltransferases (DNMTs): DNMT1, DNMT3A, and DNMT3B. Of the DNMTs, DNMT3A and DNMT3B mediate de novo DNA methylation by establishing methylation of unmodified DNA, while DNMT1 maintains the methylation pattern by preferentially methylating the nascent unmethylated strand during cell replication and DNA synthesis. ${ }^{9}$

Studies using murine models have shown that Dnmt1 is required for GC formation and Dnmt1 hypomorphic mice show increased DNA damage in GC B cells. ${ }^{10}$ Moreover, Dnmt1 is required to sustain T-cell lymphomas by preventing apoptosis in a murine MYC-induced T-cell lymphoma model. ${ }^{11}$ In terms of DLBCL, DNMT1 protein was overexpressed in a series of DLBCL cases treated with $\mathrm{CHOP}$-like regimens with concomitant expression of both DNMT1 and DNMT3B being correlated with treatment resistance. ${ }^{12}$ Priming of high-risk DLBCL patients with azacytidine, that mainly targets DNMT1 and DNMT3, followed by R-CHOP treatment have been 
shown to achieve a high complete remission rate,${ }^{13}$ and decitabine (targets DNMT1 and DNMT3) has recently completed phase I trials (ClinicalTrials.gov identifier: NCT00109824 and NCT00275080) investigating the efficacy and safety of the drug in DLBCL.

However, it is unknown whether DNMT1 expression confers prognostic value in DLBCL patients treated with R-CHOP. In this study, we set out to investigate the expression pattern of DNMT1 in DLBCL cases and its correlation with clinico-demographic parameters and survival in a multicentre series of R-CHOP-treated DLBCL patients $(n=230)$.

\subsection{MATERIALS AND METHODS}

\subsection{Patient samples}

The R-CHOP-treated primary DLBCL cases $(n=230)$ have been described previously, with 40 cases from Spain, 33 cases from Malaysia, ${ }^{14}$ and another 157 cases from Denmark. ${ }^{15}$ Immunostaining was performed with other markers previously. ${ }^{16-19}$ Clinico-demographic data of all patients are listed in Table 1. The cohort consisted of 133 males and 97 females (1.37:1 ratio) with median age of 64 years (20-91 years), and median OS and PFS (1-147 months for both) of 57 and 49 months, respectively. Reactive tonsil control tissues were obtained from the FFPE tissue archive of Department of Pathology, Universiti Sains Malaysia. All FFPE tissues used in this study were obtained in accordance with the Declaration of Helsinki and the study was approved by local ethics committees.

\subsection{Immunohistochemistry (IHC)}

IHC staining was performed using the EnVision kit (DakoCytomation, Glostrup, Denmark). Primary antibodies used, dilution factors and other IHC parameters are listed in Supplementary Table 1. DNMT1 protein expression [anti-DNMT1 antibody clone 2B5 (Abcam, Cambridge, UK)] was scored for frequency and intensity of positive tumor cells only. Frequency in $10 \%$ increment 
was scored, and staining intensity was defined as follows: 1: negative; 2 : weak/moderate; 3 : strong. For intensity scoring, weak and moderate intensities could not be robustly distinguished and hence these two intensities were considered to be in the same group for a three-tier (i.e. negative, weak/moderate, or strong) intensity system as adopted by other studies. ${ }^{20,21}$ All cases were scored by a histopathologist (E.S.C.) and independently by two researchers (K.K.W. I S.K.L.). Cases with discrepant scores (i.e. differed by $\geq 20 \%$ frequency and/or different intensity) were resolved after joint examination (E.S.C. / S.K.L.) on a multi-headed microscope. The averaged and rounded to the nearest tenth frequency of both scorings and scoring of higher intensity were selected as the final scores. The reproducibility of interobservers' agreement on DNMT1 frequency was examined by Cronbach's a analysis (SPSS Statistics v22; Chicago, IL, USA) with $\alpha$ value of 0.942 , indicating high reproducibility $(\alpha>0.9) \cdot{ }^{22}$

The DLBCL cases were previously subtyped into GCB-DLBCL or non-GCB DLBCL according to Hans $^{23}$ or Visco-Young ${ }^{24}$ algorithms for the Spanish and Malaysian series, ${ }^{14}$ and Danish series ${ }^{15}$ with the following monoclonal antibodies (mAbs): anti-CD10 mAb clone 56C6 (DakoCytomation), anti-BCL6 mAb clone PG-B6p (DakoCytomation) and clone LN22 (Leica Microsystems, Ballerup, Denmark) for the former and latter series, respectively, anti-MUM1 mAb clone MUM1p (DakoCytomation), and anti-FOXP1 mAb clone JC12 (Abcam).

\subsection{Statistical analysis}

Patients' clinico-demographic parameters according to DNMT1 expression were compared using the chi-square test for categorical variables, and the Mann-Whitney U-test for continuous variables. Correlation coefficients were assessed by Pearson $(r)$ or Spearman $(\rho)$ correlation test and $P<0.05$ was considered as significant (SPSS Statistics v22). Normality of DNMT1 expression was assessed using the histogram (GraphPad Prism v6.07; La Jolla, CA, USA) and coefficient of variation (CV; SPSS Statistics v22 software). The OS and PFS were analyzed 
using the Kaplan-Meier method and comparison between survival curves were examined using the log-rank test (GraphPad Prism v6.07). Multivariate analysis was conducted using Cox's proportional hazards model (SPSS Statistics v22).

\subsection{RESULTS}

\subsection{DNMT1 is Highly Expressed in Germinal Centers of Lymphoid Follicles}

We set out to determine the optimal primary anti-DNMT1 antibody that produces specific staining by $\mathrm{IHC}$, and four distinct antibody clones were tested on reactive tonsils. The polyclonal ab19905 and monoclonal clone 2B5 antibodies (both from Abcam, Cambridge, UK) yielded strong and specific staining of the GCs, while weak or absence of staining was observed in tonsils immunostained with the other two antibodies (clone 60B1220.1 from Abcam; clone 18/DNMT1 from BD Biosciences, San Jose, CA) even when tested at low dilutions (Supplementary Fig. 1). We adopted the mAb clone 2B5 (referenced as anti-DNMT1-2B5) for subsequent experiments as mAbs represent a constant and renewable resource for future studies. In secondary lymphoid follicles of reactive tonsil, DNMT1 was frequently and strongly expressed in the nuclei of B-cell centroblasts of the GC dark zone (DZ) with lower frequency and intensity in the GC light zone (LZ) (Fig. 1A) consistent with the immunostaining results for DNMT1 in tonsillar follicles by Shaknovich et al. ${ }^{10}$

\subsection{DNMT1 is Frequently Expressed in DLBCL with Higher Expression in the GCB-DLBCL}

\section{Subtype}

We examined DNMT1 protein expression in a multi-center series of R-CHOP-treated primary DLBCL cases $(n=230)$ with the anti-DNMT1-2B5 mAb, and found that DNMT1 was frequently expressed in DLBCL with variable frequency and intensity, and all cases showed nuclear expression (Fig. 1B). DNMT1 expression followed a non-Gaussian distribution according to visualization of the histogram that exhibited a skewed curve with the majority ( $n=128 / 230$; 
$55.7 \%$ ) of the cases displaying $\geq 60 \%$ frequency DNMT1 positivity, and coefficient of variation (CV) was calculated to be $56 \%$ (i.e., above the $50 \%$ cut-off) denoting non-Gaussian distribution

(Fig. 1C). In terms of staining intensity, 21 (9.1\%), 136 (59.1\%) and 73 (31.8\%) cases displayed negative, weak/moderate and strong DNMT1 intensity, respectively (Fig. 1D).

In terms of association with clinico-demographical parameters, higher DNMT1 frequency $(\geq 20 \%$ cut-off) was significantly associated with lower ECOG scores $(P<0.05)$ but not associated with the rest of the parameters (Fig. 2A). DLBCL cases with strong DNMT1 intensity displayed significant relationship with lower ECOG scores $(P<0.05)$ and the GCB-DLBCL subtype $(P<0.001$; Fig. 2B-C).

When compared in terms of continuous variables, higher DNMT1 frequency was associated with the GCB-DLBCL subtype ( $P=0.001)$ (Fig. 2D). However, DNMT1 was also frequently expressed in the non-GCB DLBCL subtype and the significant relationship with GCB-DLBCL subtype was mainly due to a higher proportion of GCB-DLBCL cases displaying $90-100 \%$ DNMT1 frequency (Fig. 2D).

\subsection{DNMT1 Frequency is Prognostic in R-CHOP-treated DLBCL Cases}

OS and PFS according to DNMT1 frequency were tested at every $10 \%$ increment and we observed that DNMT1 $<20 \%$ frequency $(n=33 ; 14.3 \%)$ was the cut-off most significantly associated with worse OS $(P<0.001, \mathrm{HR}: 2.86,95 \% \mathrm{Cl}: 2.38-10.02$; Fig. $3 \mathrm{~A})$ and PFS $(P<0.001$, HR: 2.40, 95\% Cl: 1.78-6.81; Fig. 3B).

Patients negative for DNMT1 expression $(n=21 ; 9.1 \%)$ demonstrated significantly worse OS and PFS compared with either strong or weak/moderate intensity immunostaining, and the outcomes did not differ significantly for strong versus weak/moderate intensities (Fig. 3C-D). In 
terms of DNMT1 intensity, comparison of patients with strong intensity ( $n=73 ; 31.7 \%$ ) versus the rest of the patients (negative and weak/moderate intensities combined; $n=157 ; 68.3 \%$ ) was not predictive of $\mathrm{OS}(P=0.127)$ and PFS $(P=0.330)$ (Supplementary Fig. 2A-B). DNMT1-positive cases $(n=209 / 230)$ showed considerably heterogeneous outcomes with $65-69 \%$ (averaged $67 \%$ ) and $56-60 \%$ (averaged 58\%) of the patients achieving 5-year OS and PFS, respectively. These indicate that $33 \%$ or $42 \%$ of DNMT1-positive patients did not achieve 5 -year OS or PFS, respectively.

As DNMT1 <20\% frequency was prognostic in this series as a whole, we assessed whether it was also predictive of outcomes within DLBCL subtypes. In GCB-DLBCL cases ( $n=118$; Hans subtyping), DNMT1 <20\% conferred poorer OS ( $P<0.001$, HR: 4.10, 95\% Cl: 3.43-47.72) and PFS ( $P=0.001, \mathrm{HR}: 3.28,95 \% \mathrm{Cl}: 2.22-24.94)$ (Supplementary Fig. 2C-D) while in non-GCB DLBCL cases $(n=112)$, DNMT1 <20\% displayed worse OS $(P=0.028, \mathrm{HR}: 2.03,95 \% \mathrm{Cl}: 1.11-$ 5.64) and not predictive of PFS ( $P=0.088$, HR: $1.73,95 \% \mathrm{Cl}: 0.91-4.19)$ (Supplementary Fig. $2 E-F)$.

Multivariate analysis showed that DNMT1 negativity or DNMT1 $<20 \%$ frequency was predictive of OS and PFS when analyzed against non-GCB DLBCL subtype or higher IPI scores $(\geq 3)$, while DNMT1 strong intensity remained insignificant consistent with univariate analysis (Table 2). DLBCL subtyping was significantly predictive of OS and PFS in this series according to both Hans and Visco-Young subtyping algorithms (Supplementary Fig. 3).

\subsection{DNMT1 is Frequently Expressed in Mitotic Cells and Significantly Associated with Ki- 67 and BCL6 Expression in Primary DLBCL Cases}

Although low DNMT1 expression or negativity conferred worse survival, DNMT1-positive cases demonstrated heterogeneous outcomes with a proportion of the cases (33-42\%) did not achieve 
5-year OS or PFS. In line with this, we observed that DNMT1 was frequently expressed in the mitotic cells where its expression was present in different phases of mitosis including prophase, metaphase and anaphase as illustrated in seven representative cases in Supplementary Fig. 4. DNMT1 intensity was visibly lower than those present in non-dividing cancer cells due to disintegrated nuclear membrane known to occur during early stages of mitosis i.e., prophase, ${ }^{25}$ potentially causing diffusion of DNMT1 protein (localized in the nucleus) into cytoplasmic regions.

These observations led us to investigate the potential co-expression of DNMT1 with the proliferation marker Ki-67 involved in cell division and ribosomal RNA synthesis. ${ }^{26}$ In reactive tonsil, Ki-67 showed stronger expression in the DZ than LZ in the same lymphoid follicles where DNMT1 was also strongly expressed in DZ compared to LZ (Fig. 4A) and both were expressed in similar population of GC B cells (Fig. 4B). In primary DLBCL cases, both DNMT1 and Ki-67 were expressed in mitotic cells (Fig. 4C).

When compared in DLBCL cases with available Ki-67 staining data $(n=155)$, DNMT1 demonstrated a strong positive correlation with Ki-67 frequency expression (Pearson $r=0.60$; Spearman $\rho=0.61 ; P<0.001$; Fig. 4D). Pearson and Spearman correlation matrix comparing the correlation values of DNMT1, Ki-67 and other markers (CD10, BCL6, GCET1, HIP1R, MUM1, FOXP1) in the same set of DLBCL cases ( $n=155$; BCL6, GCET1, HIP1R and MUM1 contained 154 assessable cases) demonstrated that the correlation values between DNMT1 and Ki-67 were the highest (Fig. 4E). Ki-67 frequency expression was not predictive of OS or PFS at every $10 \%$ cut-off increment tested in this series of 155 DLBCL cases (data not shown). Interestingly, DNMT1 also showed significantly positive correlation with frequency expression of the GCBDLBCL marker BCL6 (Pearson $r=0.44$; Spearman $\rho=0.47 ; P<0.001$; Fig. 4E). 
DNMT1 exhibited significant $(P<0.05)$ association with other GCB markers CD10 $(r=0.23 ; \rho$ $=0.21), \operatorname{GCET1}(r=0.22 ; \rho=0.24)$, and HIP1R $(r=0.28 ; \rho=0.29)$ but not significantly associated with non-GCB markers MUM1 ( $r=0.09 ; \rho=0.10)$ and FOXP1 ( $r=-0.01 ; \rho=0.02)$. Finally, within the 155 cases containing Ki-67 scores, only four cases were negative for DNMT1 and their Ki67 frequencies were $10 \%, 70 \%, 80 \%$ and $95 \%$. Although three of these cases contained high $(\geq 70 \%)$ Ki-67 frequency, we were unable to confirm the association of DNMT1 and Ki-67 in DNMT1-negative cases due to low total number of cases $(n=4)$.

\subsection{DISCUSSION}

In this study, by using a validated monoclonal anti-DNMT1-2B5 antibody, we showed that DNMT1 was frequently expressed in normal GC B cells and in primary DLBCL cases $(n=209$; 90.9\%). We observed that DLBCL cases negative for DNMT1 expression showed particularly poor survival with less than $30 \%$ of these patients achieving 5-year OS or PFS, and they formed the majority of the patients ( $n=21$ of 33 ) within the DNMT1 $<20 \%$ frequency subgroup.

Epigenetic heterogeneity, characterized by DNA methylation diversity, is initiated in normal GC B cells, and DLBCL methylome is described as variance from their corresponding cell of origin with higher variability being associated with worse clinical outcomes in DLBCL patients treated with $\mathrm{R}-\mathrm{CHOP}$ regimen, ${ }^{8,27}$ and increased risk of DLBCL relapse. ${ }^{28} \mathrm{DNMT} 1$ is the main methyltransferase highly expressed in normal GC B cells and it functions to maintain their methylome stability and prevent DNA damage. ${ }^{10}$ Moreover, global hypomethylation is a feature of DLBCL [5-methylcytosine (5-mC) content: 4.9\%] compared with normal GC B cells (5-mC content: $12.08 \%$ ) and patients with higher methylation disruption tend to exhibit ABC-DLBCL subtype. ${ }^{8}$ Taken together, low levels of DNMT1 expression or negativity in DLBCL might potentially result in high DNA methylation variability, rendering worse clinical outcomes as supported by our observations of low DNMT1 levels or negativity conferred worse survival in R- 
CHOP-treated DLBCL cases. Nonetheless, the prognostic significance of DNMT1 in DLBCL requires validation by independent studies to establish the robustness of its predictive value in R-CHOP-treated DLBCL patients.

DNMT1 was more frequently expressed in GCB-DLBCL cases comparable with the observation that patients with higher frequency DNMT1 expression had better outcomes in this series. Patient cases displaying strong DNMT1 intensity similar to that exhibited by normal DZ centroblasts were more significantly associated with GCB-DLBCL subtype. However, it remains undefined whether GCB-DLBCL cells with strong DNMT1 intensity might originate from centroblast populations in the GC. Among the common subtyping markers, DNMT1 showed the highest positive correlation with the transcription factor BCL6 in our DLBCL cohort. This correlation might reflect roles in a common pathway in GC B-cell biology or a functional relationship between the two molecules. In support of the latter, the pan-DNMT inhibitor 5azacytidine reduced BCL6 levels and cell viability in the GCB-DLBCL cell line SUDHL6. ${ }^{29}$ Moreover, BCL6 transcription is activated by cytosine methylation of its first intron which inhibits binding of the transcriptional repressor CCCTC-binding factor (CTCF), and DNMT1-mediated hypermethylation of CTCF-binding site of gene loci has been frequently demonstrated. ${ }^{30-32}$ Further studies are needed to explore these possibilities.

In terms of the relationship between DNMT1 and Ki-67, higher expression of Ki-67 in the DZ of follicular GCs has been known for over two decades. ${ }^{33,}{ }^{34}$ Higher frequency and intensity expression of DNMT1 in the DZ are consistent with the proliferative expansion known to occur in the DZ of GCs. ${ }^{35}$ Recent studies have also demonstrated significant associations of DNMT1 with a higher Ki-67 score in other malignancies including breast cancer $(n=348 ; P<0.0001),{ }^{36}$ colorectal cancer $(n=14 ; P=0.014)$ and endometrial cancer $(n=48 ; P=0.030),{ }^{37}$ while functional studies of Dnmt1-knockout or knockdown murine models have shown significant decrease of Ki- 
67-positive GC B cells ${ }^{10}$ and other cell types..$^{38-40}$ These results indicate that the frequent coexpression of DNMT1 with Ki-67 in normal B cells appears to be maintained in DLBCL cases, and suggest that DNMT1 enables the proliferation of DLBCL cells in line with our observations of frequent DNMT1 expression in DLBCL mitotic cells as well as the established requirement of DNMT1 in cellular replication. ${ }^{41,42}$ DNMT1 has also been shown to promote cell cycle in leukemia cells, ${ }^{43}$ and treatment of RAJI and U-937 lymphoma cells with a selective DNMT1 inhibitor Isofistularin-3 arrested the cells in G0/G1 phases. ${ }^{44}$

An alternative GEP classification termed as consensus cluster classification (CCC) was identified by M. Shipp's group where DLBCL can be classified into three subsets i.e. "oxidative phosphorylation" (OxPhos), "B-cell receptor/proliferation" (BCR/proliferation), and "host response" (HR) with similar 5-year survivals (50-60\%) in all three subgroups. ${ }^{45} \mathrm{~A}$ total of 2,113 genes (top 5\%) were adopted by the CCC algorithm to subgroup the cases and interestingly, these shortlisted genes included DNMT1 and MKI67 (encodes Ki-67 protein) where both genes were highly expressed in the $\mathrm{BCR} /$ proliferation subset. The $\mathrm{BCR} /$ proliferation cluster was characterized by abundant expression of molecules involved in BCR signaling cascade (e.g. CD19, SYK), cell cycle regulatory genes (e.g. CDK2, CCNB2) and DNA repair genes (e.g. H2AX, PTIP). The role of DNMT1 in promoting cell cycle activation has been frequently documented, ${ }^{46,47}$ and Dnmt1 deficiency induces DNA damage of murine GC B cells in vivo. ${ }^{10}$ These suggest that DLBCL cases co-expressing DNMT1 and Ki67 might represent BCR/proliferation subgroup of DLBCL cases, however, such postulation requires further experimental verifications.

DNMT1 has been proposed as a viable cancer target as it is involved in the proliferation or survival of various malignant cells including breast cancer, ${ }^{38}$ renal cell carcinoma, ${ }^{48}$ pharyngeal cancer $^{49}$ and various other tumors (reviewed by Subramaniam et al.). ${ }^{50}$ Although very low levels 
(<20\% DNMT1 frequency) or DNMT1 negativity conferred worse survival, 33-42\% of DNMT1positive cases did not achieve 5-year OS or PFS, DNMT1 was positive in $90.9 \%$ of DLBCL cases with majority of them demonstrating $\geq 60 \%$ frequency and its expression was associated with the proliferation marker Ki-67. DNMT1 might thus be considered as a potentially ubiquitous DLBCL target associated with cellular proliferation.

DNMT1 is an FDA-approved druggable protein ${ }^{51}$ and discovery of novel specific anti-DNMT1 small molecule inhibitors is an active area of investigation in which high-throughput screening and DNMT1 functional assays have recently produced numerous pre-clinical DNMT1 inhibitors such as Isofistularin-3, ${ }^{44}$ antroquinonol $D,{ }^{52}$ triclabendazole, ${ }^{53}$ laccaic acid $A^{54}$ and others. ${ }^{55-59}$ In addition, the resolved crystal structures of DNMT1 (Protein Data Bank ID: 3SWR or 4DA4) have enabled characterization of DNMT1 inhibitors' mode of action and precise binding sites. ${ }^{44,52,59}$ These novel anti-DNMT1 inhibitors might represent future investigation avenues in targeting DNMT1-positive DLBCL cases for destruction, and we suggest that DNMT1 immunohistochemistry with a validated anti-DNMT1 mAb (clone 2B5) can be considered to guide future usage of anti-DNMT1 targeting agents. However, as DNMT1 is also ubiquitously expressed in normal GC B cells, targeting DNMT1 might result in depletion of normal activated B cells and increases the likelihood of immunosuppression as a side effect.

In conclusion, our studies support further investigations on the requirement of DNMT1 for the survival of DLBCL cells as well as the potential of novel specific anti-DNMT1 agents against the proliferation and viability of DLBCL cells.

\section{Acknowledgements}

The technical assistance of Jamaliah binti Lin from Department of Pathology, Universiti Sains Malaysia, is gratefully acknowledged. This work was supported by Research University 
(1001/PPSP/813054) and Short Term (304/PPSP/61312002) grants, Universiti Sains Malaysia, awarded to K.K.W. Research by T.M.G and M.B.M was supported by Odense University Hospital (grant no. 932-001). Research by C.H.L was supported by Ikerbasque, Basque Foundation for Science, Instituto de salud Carlos III (Proyectos integrados de excelencia; PIE13/00048) and Diputación Foral de Gipuzkoa. Research by A.H.B was supported by Bloodwise Programme grant (13047).

\section{Author contributions}

S.K.L performed and optimized experiments, analyzed data and wrote the methodologies. E.S.C interpreted staining of DLBCL cases and non-malignant tissues. C.H.L, M.A.A, A.G, M.P.P provided tissue microarrays of the Spanish series of DLBCL cases and their information. M.S.M.S, A.H provided the Malaysian series of DLBCL cases and their information. T.M.G, M.B.B, L.M.P provided tissue microarrays of the Danish series of DLBCL cases and their information. A.H.B provided FOXP1 and HIP1R immunostaining data. K.K.W conceived and designed the research, analyzed data and wrote the manuscript. All authors critically read and approved the final draft of the manuscript.

\section{Disclosure of interest}

The authors declare no conflict of interest.

\section{REFERENCES}

[1] Swerdlow SH, Campo E, Pileri SA, et al. The 2016 revision of the World Health Organization classification of lymphoid neoplasms. Blood. 2016; 127: 2375-90.

[2] Camicia R, Winkler HC, Hassa PO. Novel drug targets for personalized precision medicine in relapsed/refractory diffuse large B-cell lymphoma: a comprehensive review. Mol Cancer. 2015; 14: 207.

[3] Alizadeh AA, Eisen MB, Davis RE, et al. Distinct types of diffuse large B-cell lymphoma identified by gene expression profiling. Nature. 2000; 403: 503-11. 
[4] Gutierrez-Garcia G, Cardesa-Salzmann T, Climent F, et al. Gene-expression profiling and not immunophenotypic algorithms predicts prognosis in patients with diffuse large B-cell lymphoma treated with immunochemotherapy. Blood. 2011; 117: 4836-43.

[5] Gifford GK, Gill AJ, Stevenson WS. Molecular subtyping of diffuse large B-cell lymphoma: update on biology, diagnosis and emerging platforms for practising pathologists. Pathology. 2016; 48: 5-16.

[6] Jiang Y, Melnick A. The epigenetic basis of diffuse large B-cell lymphoma. Semin Hematol. 2015; 52: 86-96.

[7] Shaknovich R, Geng H, Johnson NA, et al. DNA methylation signatures define molecular subtypes of diffuse large B-cell lymphoma. Blood. 2010; 116: e81-9.

[8] Chambwe N, Kormaksson M, Geng H, et al. Variability in DNA methylation defines novel epigenetic subgroups of DLBCL associated with different clinical outcomes. Blood. 2014; 123: 1699-708.

[9] Suarez-Alvarez B, Rodriguez RM, Fraga MF, et al. DNA methylation: a promising landscape for immune system-related diseases. Trends Genet. 2012; 28: 506-14.

[10] Shaknovich R, Cerchietti L, Tsikitas L, et al. DNA methyltransferase 1 and DNA methylation patterning contribute to germinal center B-cell differentiation. Blood. 2011; 118: 3559-69.

[11] Peters SL, Hlady RA, Opavska J, et al. Essential role for Dnmt1 in the prevention and maintenance of MYC-induced T-cell lymphomas. Mol Cell Biol. 2013; 33: 4321-33.

[12] Amara K, Ziadi S, Hachana M, et al. DNA methyltransferase DNMT3b protein overexpression as a prognostic factor in patients with diffuse large B-cell lymphomas. Cancer Sci. 2010; 101: 1722-30.

[13] Clozel T, Yang S, Elstrom RL, et al. Mechanism-based epigenetic chemosensitization therapy of diffuse large B-cell lymphoma. Cancer Discov. 2013; 3: 1002-19.

[14] Wong KK, Ch'ng ES, Loo SK, et al. Low HIP1R mRNA and protein expression are associated with worse survival in diffuse large B-cell lymphoma patients treated with R-CHOP. Exp Mol Pathol. 2015; 99: 537-45.

[15] Green TM, Young KH, Visco C, et al. Immunohistochemical double-hit score is a strong predictor of outcome in patients with diffuse large B-cell lymphoma treated with rituximab plus cyclophosphamide, doxorubicin, vincristine, and prednisone. J Clin Oncol. 2012; 30: 3460-7. [16] Wong KK, Gascoyne DM, Brown PJ, et al. Reciprocal expression of the endocytic protein HIP1R and its repressor FOXP1 predicts outcome in R-CHOP-treated diffuse large B-cell lymphoma patients. Leukemia. 2014; 28: 362-72.

[17] Brown PJ, Wong KK, Felce SL, et al. FOXP1 suppresses immune response signatures and MHC class II expression in activated B-cell-like diffuse large B-cell lymphomas. Leukemia. 2016; 30: 605-16.

[18] Wong KK, Gascoyne DM, Soilleux EJ, et al. FOXP2-positive diffuse large B-cell lymphomas exhibit a poor response to R-CHOP therapy and distinct biological signatures. Oncotarget. 2016; 7: 52940-56.

[19] Loo SK, Ch'ng ES, Md Salleh MS, et al. TRPM4 expression is associated with activated B cell subtype and poor survival in diffuse large B cell lymphoma. Histopathology. 2017; 71: 98-111.

[20] Conesa-Zamora P, Garcia-Solano J, Garcia-Garcia F, et al. Expression profiling shows differential molecular pathways and provides potential new diagnostic biomarkers for colorectal serrated adenocarcinoma. Int J Cancer. 2013; 132: 297-307.

[21] Dogan AS, Onder E, Arikok AT, et al. Claudin-1 expressions decrease in pterygium with respect to normal conjunctiva. Cutan Ocul Toxicol. 2016: 1-4.

[22] Lawrie $\mathrm{CH}$, Ballabio $\mathrm{E}$, Soilleux $\mathrm{E}$, et al. Inter- and intra-observational variability in immunohistochemistry: a multicentre analysis of diffuse large B-cell lymphoma staining. Histopathology. 2012; 61: 18-25.

[23] Hans CP, Weisenburger DD, Greiner TC, et al. Confirmation of the molecular classification of diffuse large B-cell lymphoma by immunohistochemistry using a tissue microarray. Blood. 2004; 103 : 275-82. 
[24] Visco C, Li Y, Xu-Monette ZY, et al. Comprehensive gene expression profiling and immunohistochemical studies support application of immunophenotypic algorithm for molecular subtype classification in diffuse large B-cell lymphoma: a report from the International DLBCL RituximabCHOP Consortium Program Study. Leukemia. 2012; 26: 2103-13.

[25] van Amerongen MJ, Engel FB. Features of cardiomyocyte proliferation and its potential for cardiac regeneration. J Cell Mol Med. 2008; 12: 2233-44.

[26] Penault-Llorca F, Radosevic-Robin N. Ki67 assessment in breast cancer: an update. Pathology. 2017; 49: 166-71.

[27] De S, Shaknovich R, Riester M, et al. Aberration in DNA methylation in B-cell lymphomas has a complex origin and increases with disease severity. PLoS Genet. 2013; 9: e1003137.

[28] Pan H, Jiang Y, Boi M, et al. Epigenomic evolution in diffuse large B-cell lymphomas. Nat Commun. 2015; 6: 6921.

[29] Lai AY, Fatemi M, Dhasarathy A, et al. DNA methylation prevents CTCF-mediated silencing of the oncogene BCL6 in B cell lymphomas. J Exp Med. 2010; 207: 1939-50.

[30] Shukla S, Kavak E, Gregory M, et al. CTCF-promoted RNA polymerase Il pausing links DNA methylation to splicing. Nature. 2011; 479: 74-9.

[31] Zampieri M, Guastafierro T, Calabrese R, et al. ADP-ribose polymers localized on Ctcf-Parp1Dnmt1 complex prevent methylation of Ctcf target sites. Biochem J. 2012; 441: 645-52.

[32] Min HY, Lee SC, Woo JK, et al. Essential Role of DNA Methyltransferase 1-mediated Transcription of Insulin-like Growth Factor 2 in Resistance to Histone Deacetylase Inhibitors. Clin Cancer Res. 2017; 23: 1299-311.

[33] Liu YJ, Johnson GD, Gordon J, et al. Germinal centres in T-cell-dependent antibody responses. Immunol Today. 1992; 13: 17-21.

[34] Hardie DL, Johnson GD, Khan M, et al. Quantitative analysis of molecules which distinguish functional compartments within germinal centers. Eur J Immunol. 1993; 23: 997-1004.

[35] Dominguez-Sola D, Kung J, Holmes AB, et al. The FOXO1 Transcription Factor Instructs the Germinal Center Dark Zone Program. Immunity. 2015; 43: 1064-74.

[36] Shin E, Lee Y, Koo JS. Differential expression of the epigenetic methylation-related protein DNMT1 by breast cancer molecular subtype and stromal histology. J Transl Med. 2016; 14: 87.

[37] Joensuu El, Nieminen TT, Lotsari JE, et al. Methyltransferase expression and tumor suppressor gene methylation in sporadic and familial colorectal cancer. Genes Chromosomes Cancer. 2015; 54: 77687.

[38] Pathania R, Ramachandran S, Elangovan S, et al. DNMT1 is essential for mammary and cancer stem cell maintenance and tumorigenesis. Nat Commun. 2015; 6: 6910.

[39] Noguchi H, Murao N, Kimura A, et al. DNA Methyltransferase 1 Is Indispensable for Development of the Hippocampal Dentate Gyrus. J Neurosci. 2016; 36: 6050-68.

[40] Kaji K, Factor VM, Andersen JB, et al. DNMT1 is a required genomic regulator for murine liver histogenesis and regeneration. Hepatology. 2016; 64: 582-98.

[41] Sharif J, Muto M, Takebayashi S, et al. The SRA protein Np95 mediates epigenetic inheritance by recruiting Dnmt1 to methylated DNA. Nature. 2007; 450: 908-12.

[42] Schermelleh L, Haemmer A, Spada F, et al. Dynamics of Dnmt1 interaction with the replication machinery and its role in postreplicative maintenance of DNA methylation. Nucleic Acids Res. 2007; 35: 4301-12.

[43] Vispe S, Deroide A, Davoine E, et al. Consequences of combining siRNA-mediated DNA methyltransferase 1 depletion with 5-aza-2'-deoxycytidine in human leukemic KG1 cells. Oncotarget. 2015; 6: 15265-82. 
[44] Florean C, Schnekenburger M, Lee JY, et al. Discovery and characterization of Isofistularin-3, a marine brominated alkaloid, as a new DNA demethylating agent inducing cell cycle arrest and sensitization to TRAIL in cancer cells. Oncotarget. 2016; 7: 24027-49.

[45] Monti S, Savage KJ, Kutok JL, et al. Molecular profiling of diffuse large B-cell lymphoma identifies robust subtypes including one characterized by host inflammatory response. Blood. 2005; 105: 1851-61.

[46] Barra V, Schillaci T, Lentini L, et al. Bypass of cell cycle arrest induced by transient DNMT1 posttranscriptional silencing triggers aneuploidy in human cells. Cell Div. 2012; 7: 2.

[47] Wang X, Li B. DNMT1 regulates human endometrial carcinoma cell proliferation. Onco Targets Ther. 2017; 10: 1865-73.

[48] Li M, Wang Y, Song Y, et al. Aberrant DNA methyltransferase 1 expression in clear cell renal cell carcinoma development and progression. Chin J Cancer Res. 2014; 26: 371-81.

[49] Chen CC, Chen WC, Wang WH, et al. Role of DNA methyltransferase 1 in pharyngeal cancer related to treatment resistance. Head Neck. 2011; 33: 1132-43.

[50] Subramaniam D, Thombre R, Dhar A, et al. DNA methyltransferases: a novel target for prevention and therapy. Front Oncol. 2014; 4: 80.

[51] Uhlen M, Fagerberg L, Hallstrom BM, et al. Proteomics. Tissue-based map of the human proteome. Science. 2015; 347: 1260419.

[52] Wang SC, Lee TH, Hsu CH, et al. Antroquinonol D, isolated from Antrodia camphorata, with DNA demethylation and anticancer potential. J Agric Food Chem. 2014; 62: 5625-35.

[53] Fagan RL, Wu M, Chedin F, et al. An ultrasensitive high throughput screen for DNA methyltransferase 1-targeted molecular probes. PLoS One. 2013; 8: e78752.

[54] Fagan RL, Cryderman DE, Kopelovich L, et al. Laccaic acid A is a direct, DNA-competitive inhibitor of DNA methyltransferase 1. J Biol Chem. 2013; 288: 23858-67.

[55] Kilgore JA, Du X, Melito L, et al. Identification of DNMT1 selective antagonists using a novel scintillation proximity assay. J Biol Chem. 2013; 288: 19673-84.

[56] Chen S, Wang Y, Zhou W, et al. Identifying novel selective non-nucleoside DNA methyltransferase 1 inhibitors through docking-based virtual screening. J Med Chem. 2014; 57: 9028-41. [57] Weng JR, Lai IL, Yang HC, et al. Identification of kazinol Q, a natural product from Formosan plants, as an inhibitor of DNA methyltransferase. Phytother Res. 2014; 28: 49-54.

[58] Zhu B, Ge J, Yao SQ. Developing new chemical tools for DNA methyltransferase 1 (DNMT 1): a small-molecule activity-based probe and novel tetrazole-containing inhibitors. Bioorg Med Chem. 2015; 23: 2917-27.

[59] Joshi M, Rajpathak SN, Narwade SC, et al. Ensemble-Based Virtual Screening and Experimental Validation of Inhibitors Targeting a Novel Site of Human DNMT1. Chem Biol Drug Des. 2016; 88: 5-16. 
Table 1: Clinico-demographic characteristics and outcome of DLBCL patients treated with R$\mathrm{CHOP}(\mathrm{n}=230)$. ULN: upper limit of normal; HR: hazard ratio; $\mathrm{Cl}$ : confidence interval. $P<0.05$ is emboldened.

\begin{tabular}{|c|c|c|c|c|c|c|c|}
\hline \multirow{2}{*}{ Characteristics } & \multirow{2}{*}{ n (\%) } & \multicolumn{3}{|c|}{ OS } & \multicolumn{3}{|c|}{ PFS } \\
\hline & & HR & $95 \% \mathrm{Cl}$ & $P$-value & HR & $95 \% \mathrm{Cl}$ & $P$-value \\
\hline \multicolumn{8}{|l|}{ Age (years) } \\
\hline Median (range) & $64(20-91)$ & \multirow{3}{*}{2.73} & \multirow{3}{*}{$1.66-4.49$} & \multirow{3}{*}{$<0.001$} & \multirow{3}{*}{2.13} & \multirow{3}{*}{$1.38-3.30$} & \multirow{3}{*}{0.001} \\
\hline$\leq 60$ & $98(43)$ & & & & & & \\
\hline$>60$ & $132(57)$ & & & & & & \\
\hline \multicolumn{8}{|l|}{ Sex } \\
\hline Female & $97(42)$ & \multirow{2}{*}{0.72} & \multirow{2}{*}{$0.47-1.10$} & \multirow{2}{*}{0.131} & \multirow{2}{*}{0.73} & \multirow{2}{*}{$0.49-1.09$} & \multirow{2}{*}{0.125} \\
\hline Male & $133(58)$ & & & & & & \\
\hline \multicolumn{8}{|l|}{ LDH } \\
\hline$\leq U L N$ & $114(50)$ & \multirow[t]{2}{*}{1.63} & \multirow{2}{*}{$1.05-2.52$} & \multirow{2}{*}{0.028} & \multirow{2}{*}{1.83} & \multirow{2}{*}{$1.22-2.74$} & \multirow[t]{2}{*}{0.003} \\
\hline$>$ ULN & $116(50)$ & & & & & & \\
\hline \multicolumn{8}{|c|}{ Extranodal involvement } \\
\hline $0-1$ & $193(84)$ & \multirow{2}{*}{1.87} & \multirow{2}{*}{$1.12-3.13$} & \multirow{2}{*}{0.017} & \multirow[t]{2}{*}{1.84} & \multirow[t]{2}{*}{$1.14-2.96$} & \multirow[t]{2}{*}{0.013} \\
\hline$\geq 2$ & $37(16)$ & & & & & & \\
\hline \multicolumn{8}{|l|}{ ECOG status } \\
\hline $0-1$ & $169(73)$ & 2.59 & $1.66-4.03$ & $<0.001$ & 2.13 & $1.40-3.23$ & $<0.001$ \\
\hline$\geq 2$ & $61(27)$ & & & & & & \\
\hline Stage & & & & & & & \\
\hline I-II & $112(49)$ & 1.54 & $0.99-2.38$ & 0.054 & 1.96 & $1.30-2.96$ & 0.001 \\
\hline III-IV & $118(51)$ & & & & & & \\
\hline IPI & & & & & & & \\
\hline $0-2$ & $148(64)$ & 2.79 & $1.80-4.30$ & $<0.001$ & 2.63 & $1.76-3.92$ & $<0.001$ \\
\hline $3-5$ & $82(36)$ & & & & & & \\
\hline
\end{tabular}


Table 2: DNMT1 negativity, frequency and intensity multivariate analysis for OS and PFS in DLBCL patients ( $n=230$ ) treated with R-CHOP. Non-GCB: Non-GCB DLBCL; Hans: Hans algorithm; VY: Visco-Young algorithm; HR: hazard ratio; $\mathrm{Cl}$ : confidence interval; $P<0.05$ is emboldened.

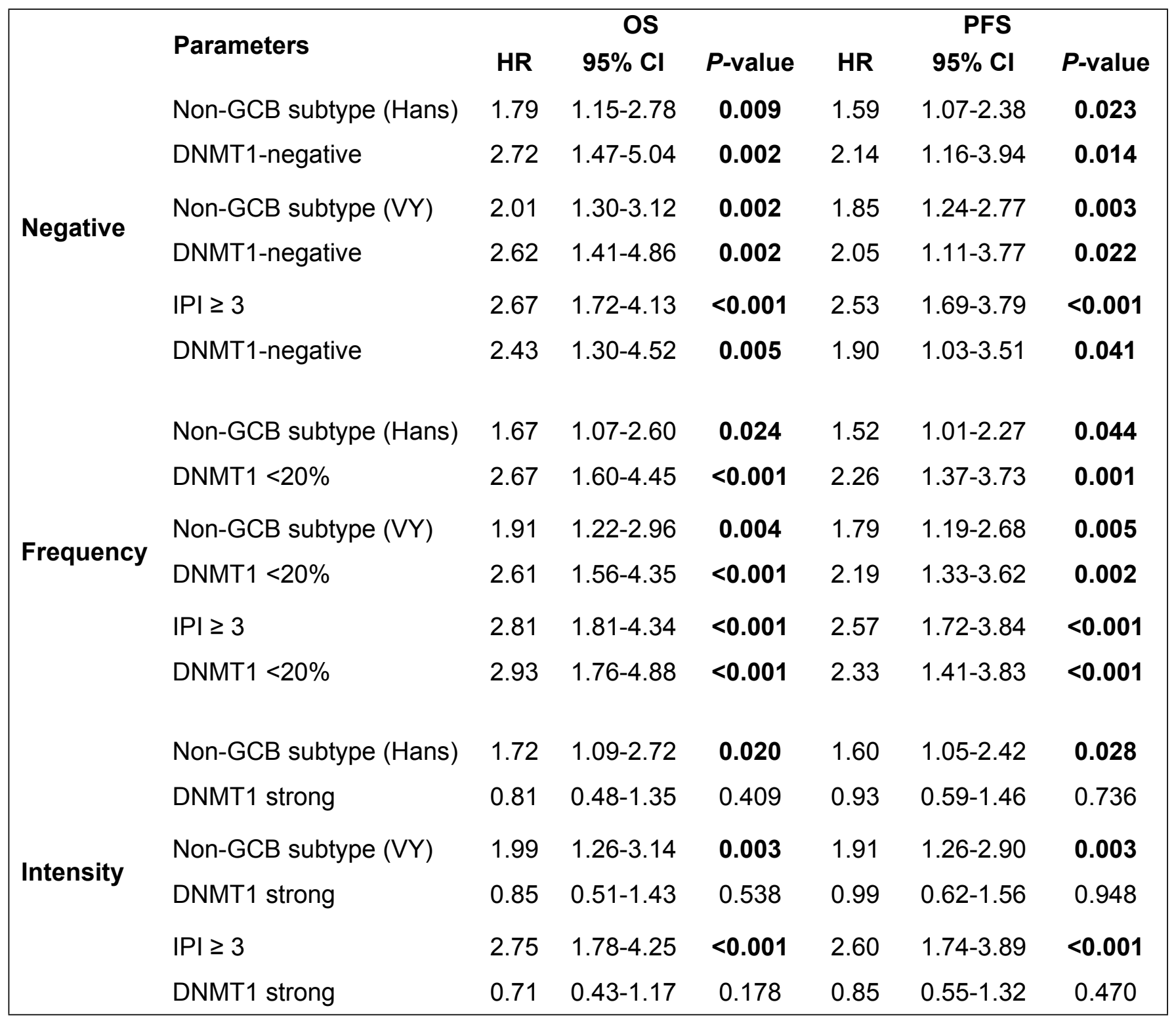




\section{FIGURE LEGENDS}

Fig. 1. Immunohistochemical staining of DNMT1 in reactive tonsils and primary DLBCL cases. (A) Reactive tonsil (control tissue) immunostained for DNMT1. The right panel corresponds to the boxed region at higher magnification. (B) Representative DLBCL cases immunostained for DNMT1 with various levels of intensity and frequency. (C-D) DNMT1 frequency (C) or intensity (D; Neg: Negative; W/M: Weak or moderate; S: Strong) distribution in primary DLBCL cases $(n=230)$.

Fig. 2. Relationship of DNMT1 expression with clinico-demographical characteristics and DLBCL subtypes. (A-B) Association of DNMT1 frequency (A; categorical variables) or intensity (B) with clinico-demographic characteristics of primary DLBCL cases $(n=230)$. F: Female; M: Male; LDH: Lactate dehydrogenase; ULN: Upper limit of normal; E/N: Extranodal; ECOG: Eastern Cooperative Oncology Group performance status; IPI: International Prognostic Index; GCB: GCB-DLBCL; NGCB: Non-GCB DLBCL; VY: Visco-Young; Neg: Negative; *: $P<0.05$; **: $P<0.01$; NS: Not significant; (C-D) Comparison of DNMT1 intensity (C; Neg: Negative; W/M: Weak or moderate; S: Strong) or frequency (D; continuous variables) in GCB- or non-GCB DLBCL cases according to Hans or Visco-Young (VY) subtyping algorithms.

Fig. 3. Association of DNMT1 expression with survival in R-CHOP-treated DLBCL cases $(n=230)$. (A-B) Survival according to DNMT1 frequency at $20 \%$ cut-off for OS (A) and PFS (B) (HR: Hazard ratio); (C-D) Survival according to DNMT1 intensity for OS (C) and PFS (D) (Neg: Negative; W/M: Weak/moderate; S: Strong).

Fig. 4. Association of DNMT1 expression with Ki-67 or BCL6 protein expression. (A-B) Ki-67 and DNMT1 protein expression in the same region of reactive tonsil; (C) Ki-67 and DNMT1 protein expression in the same case of primary DLBCL with both proteins staining similar 
populations of malignant cells and mitotic cells are denoted by arrows; (D) Distribution of Ki-67 frequency according to each $10 \%$ increment level of DNMT1 frequency expression in primary DLBCL cases $(n=155)$. Each bar joined by a connecting line denotes the median value of DNMT1 frequency; (E) Correlation of DNMT1 with other markers according to Pearson correlation (top half) or Spearman correlation (bottom half) in primary DLBCL cases $(n=155$; BCL6, GCET1, HIP1R and MUM1 contained 154 evaluable cases), and significant $(P<0.05)$ correlation values are emboldened and underlined.

Supplementary Table 1: Antibodies and experimental parameters used for IHC. aa: amino acid.

Supplementary Fig. 1. Reactive tonsils immunostained with anti-DNMT1 antibodies: (A) Polyclonal ab19905; (B) Clone 2B5 ; (C) Clone 60B1220.1; (D) Clone 18/DNMT1. The right panel corresponds to the boxed region at higher magnification.

Supplementary Fig. 2. OS (A) and PFS (B) according to strong DNMT1 intensity versus DNMT1 negative, weak and moderate intensity cases (Neg: Negative; W: Weak; M: Moderate; HR: Hazard ratio). Survival according to DNMT1 frequency within DLBCL subtypes stratified according to Hans algorithm in GCB-DLBCL (C-D) or non-GCB DLBCL (E-F) subtype (HR: Hazard ratio).

Supplementary Fig. 3. OS and PFS of GCB- versus non-GCB DLBCL subtypes stratified by Hans (A-B) or Visco-Young (VY; C-D) algorithm. HR: Hazard ratio.

Supplementary Fig. 4. Seven representative DLBCL cases immunostained for DNMT1 at different stages of mitosis (prophase, metaphase, anaphase/telophase). 
Fig. 1
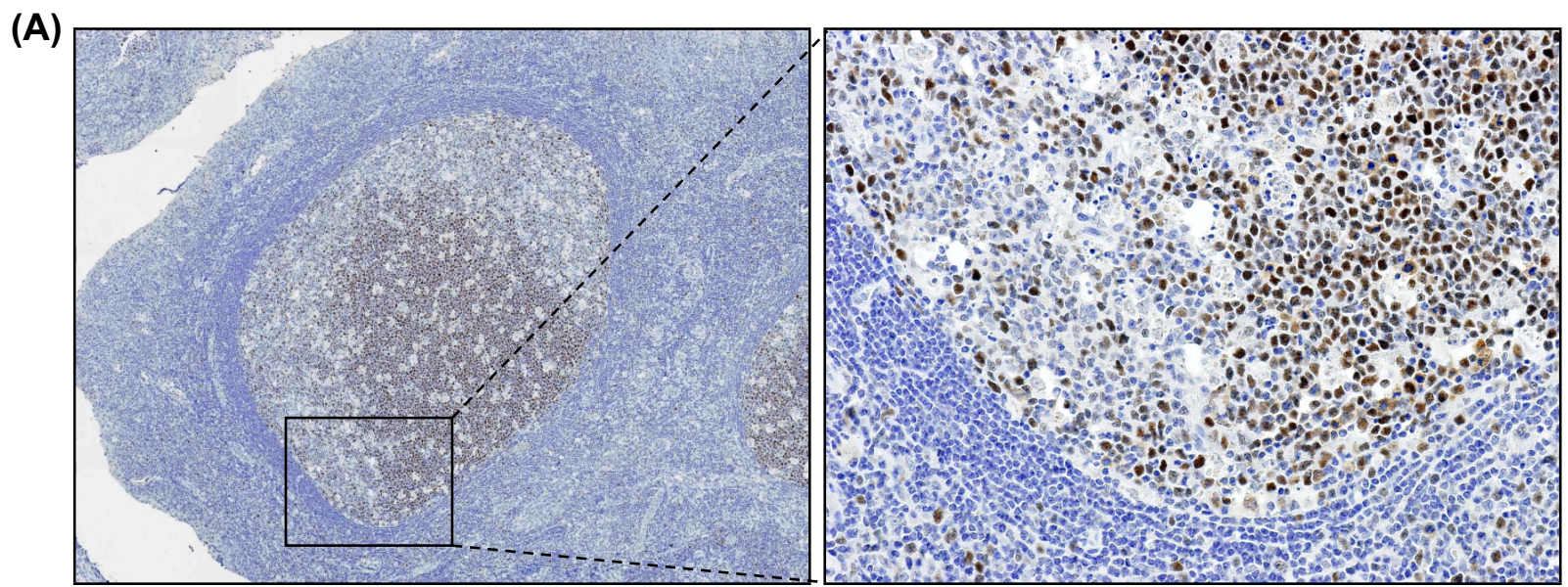

(B)

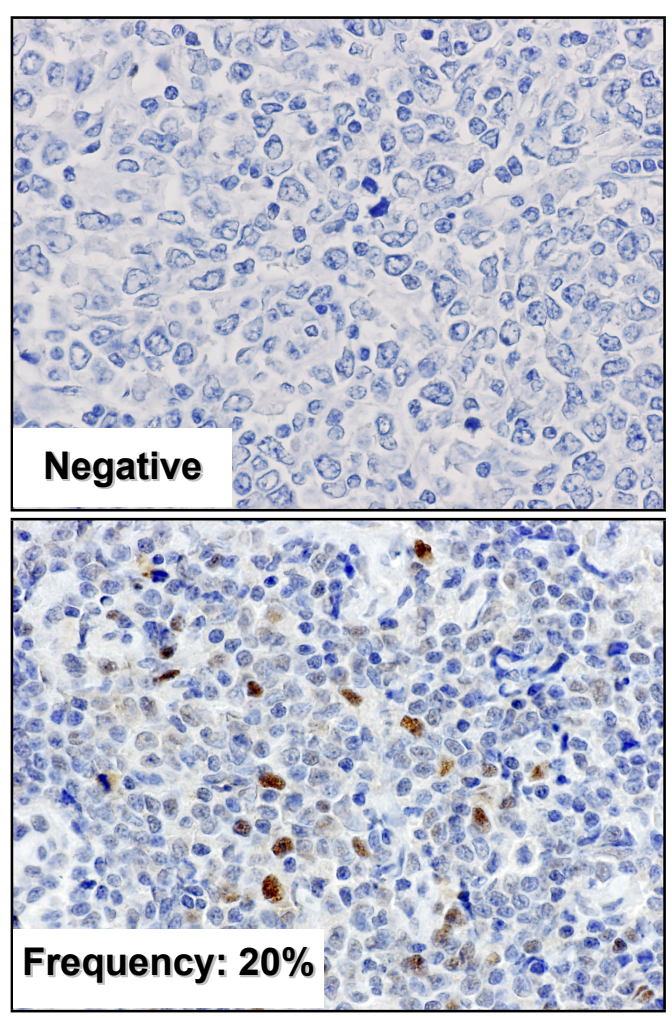

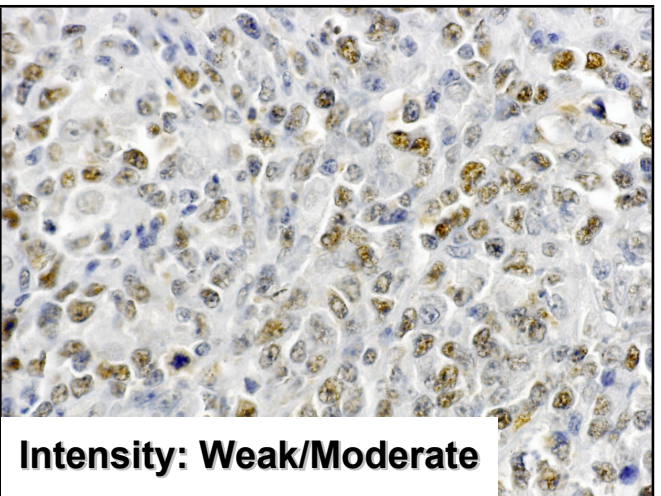

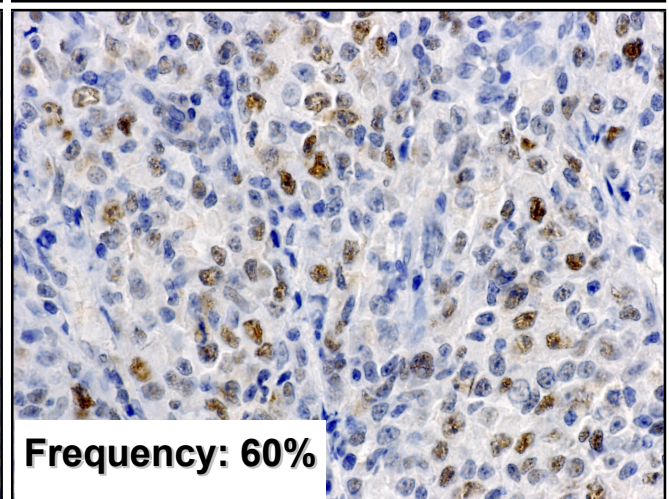

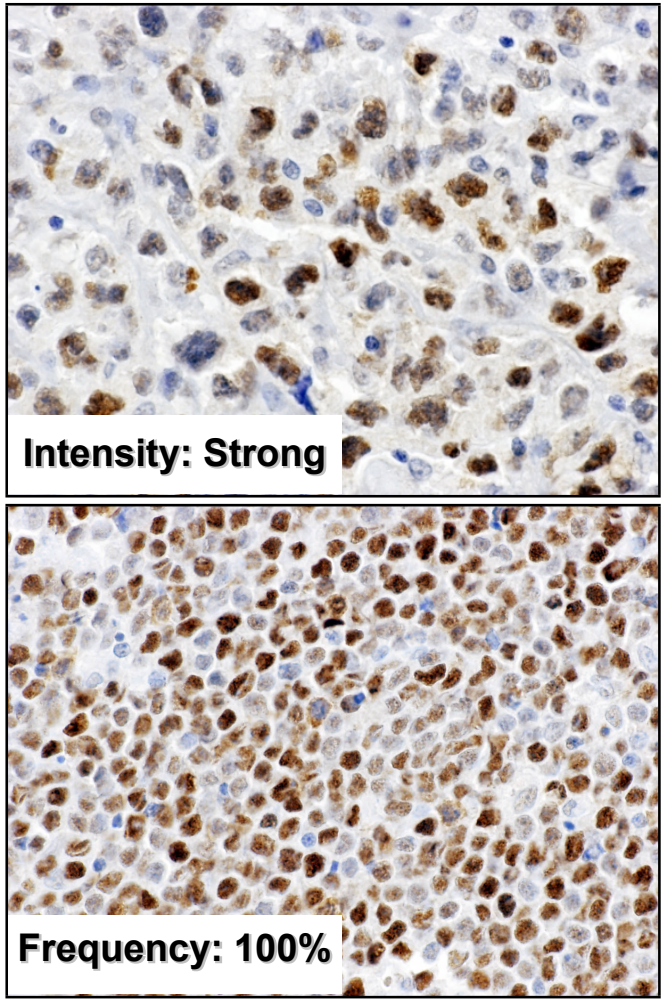

(C)

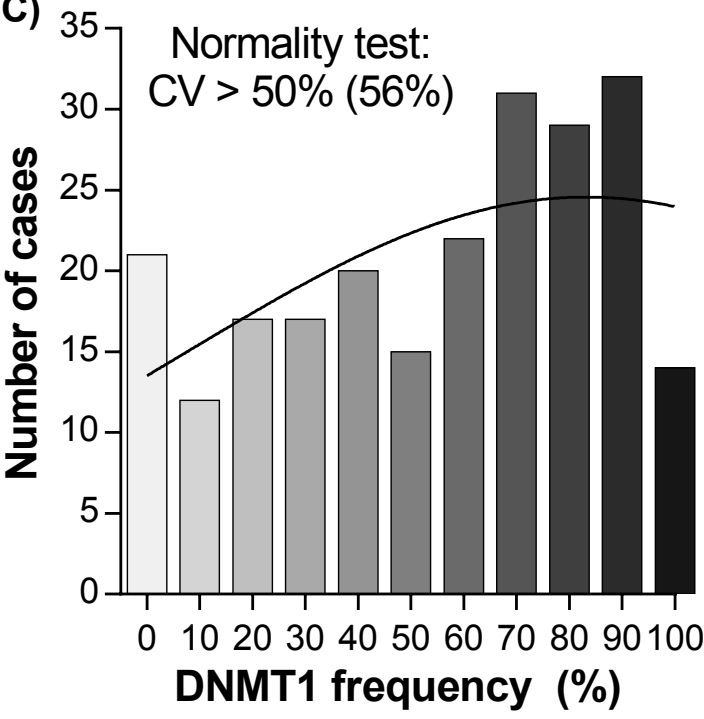

(D)

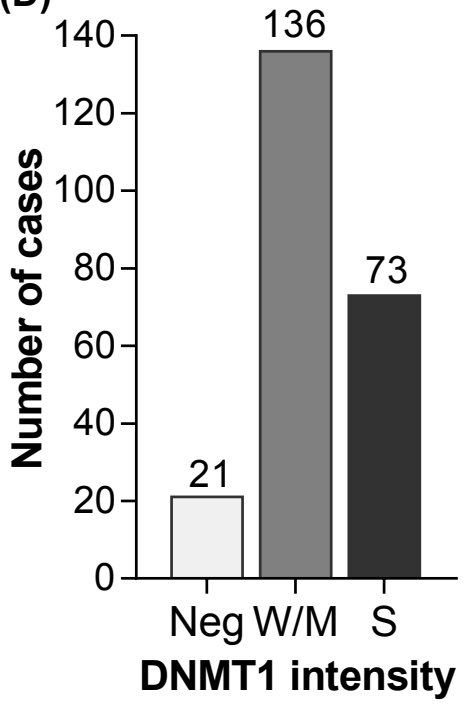


Fig. 2

(A)

Frequency $>20 \%$

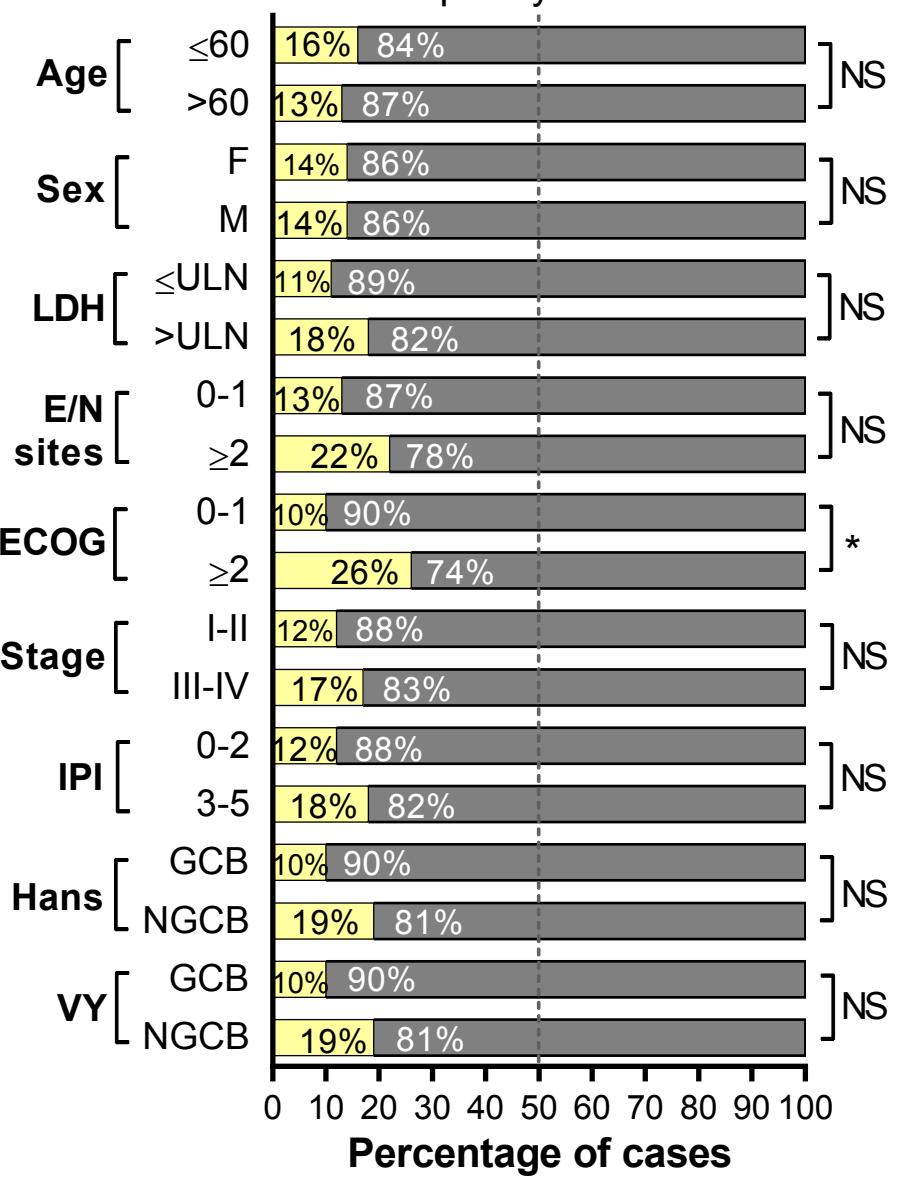

(C)

DNMT1 intensity

\section{GCB}

Non-GCB

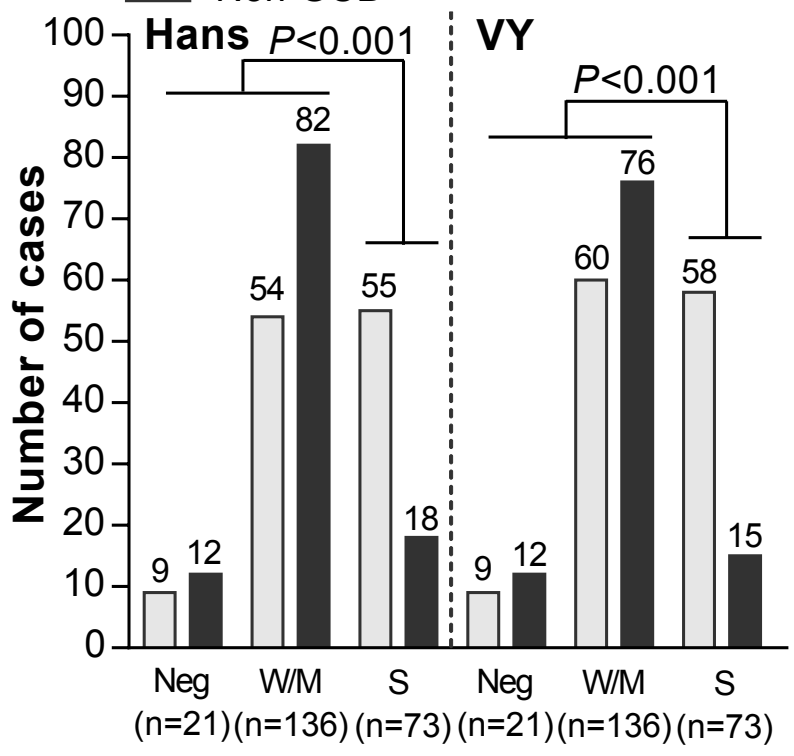

(B)

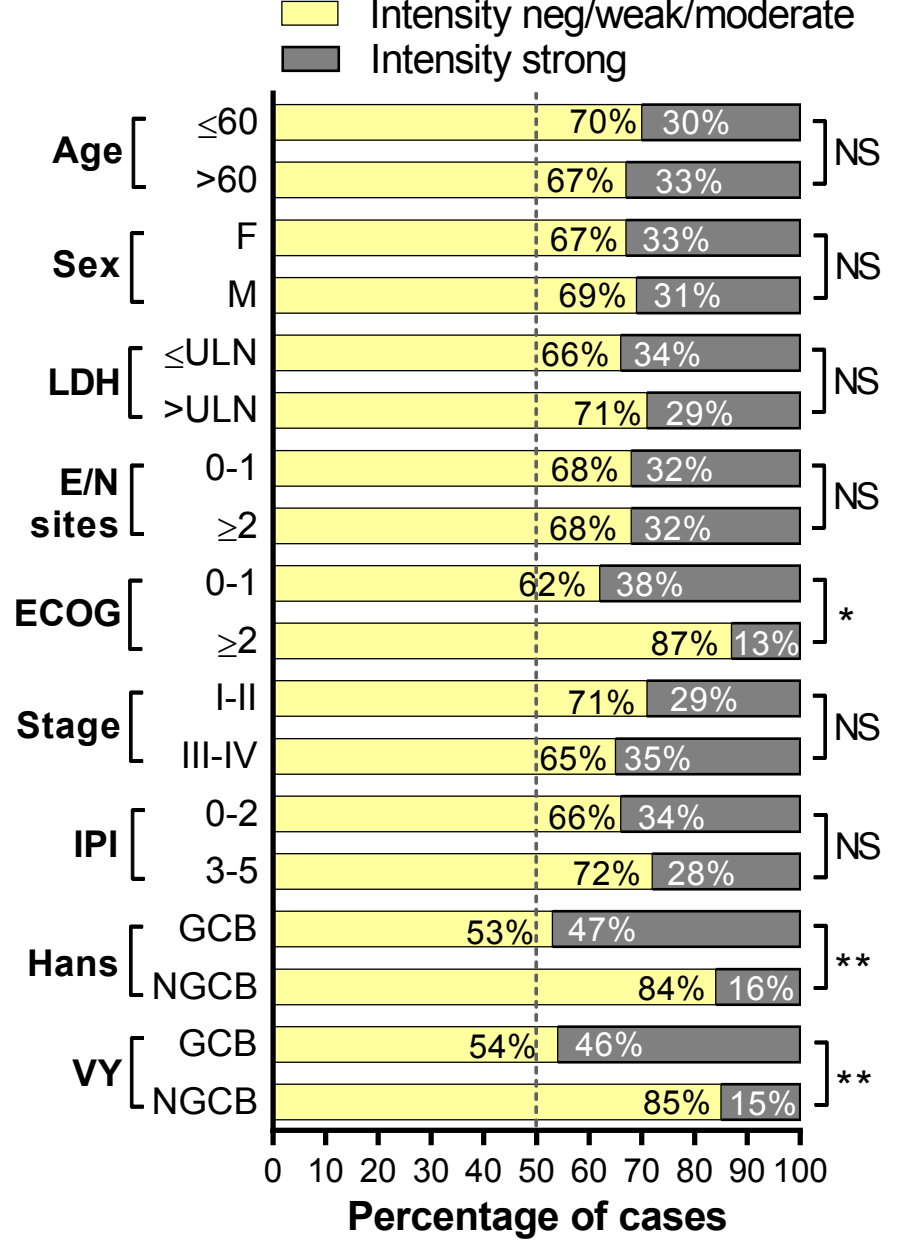

(D)

DNMT1 frequency (\%)

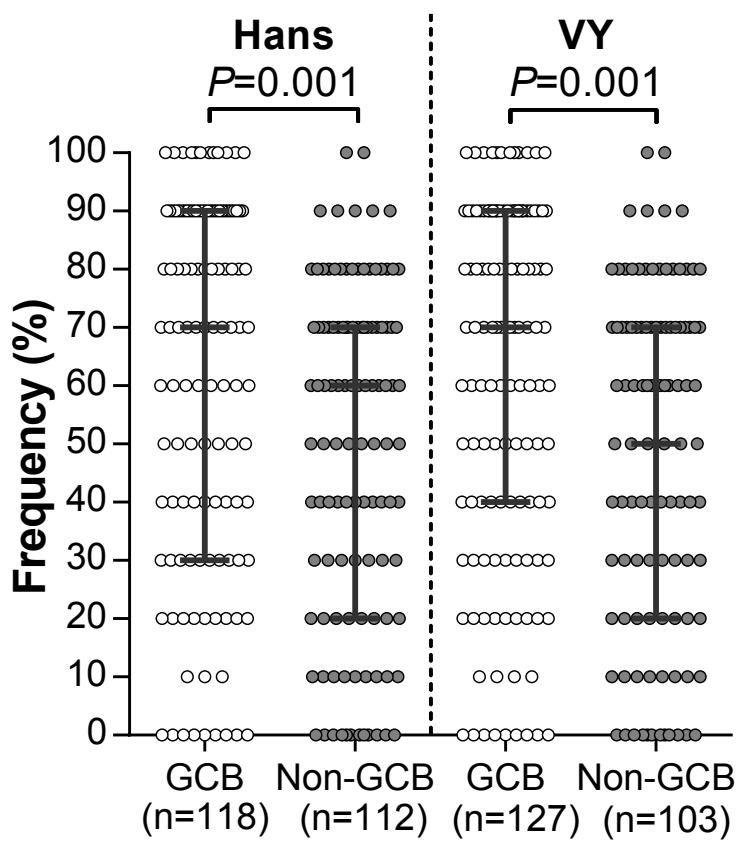


Fig. 3

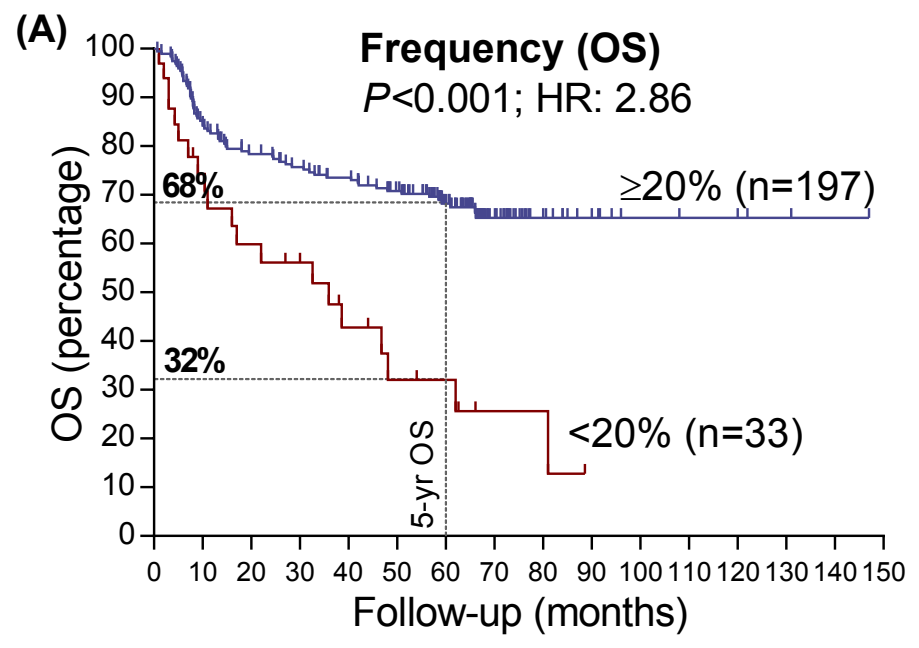

(C)

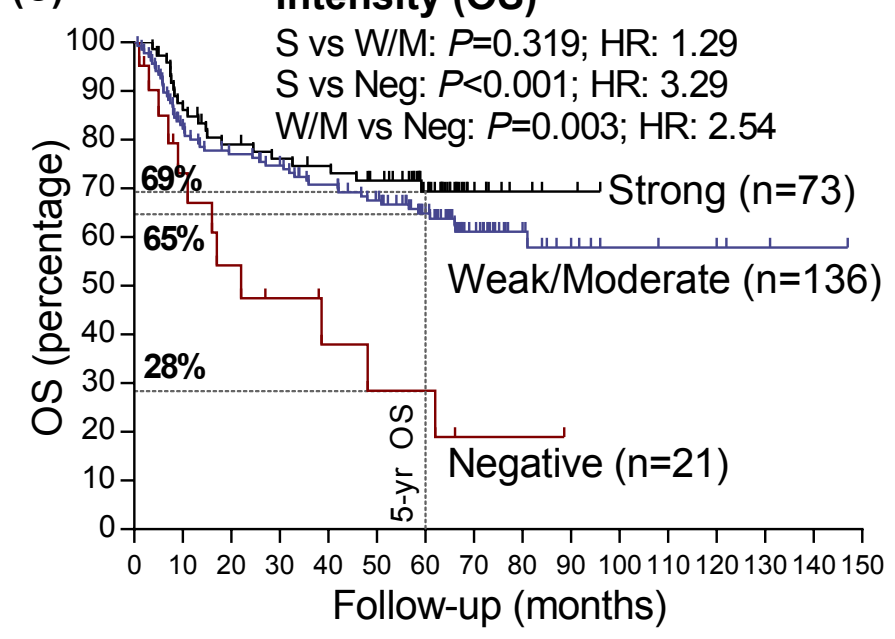

(B)

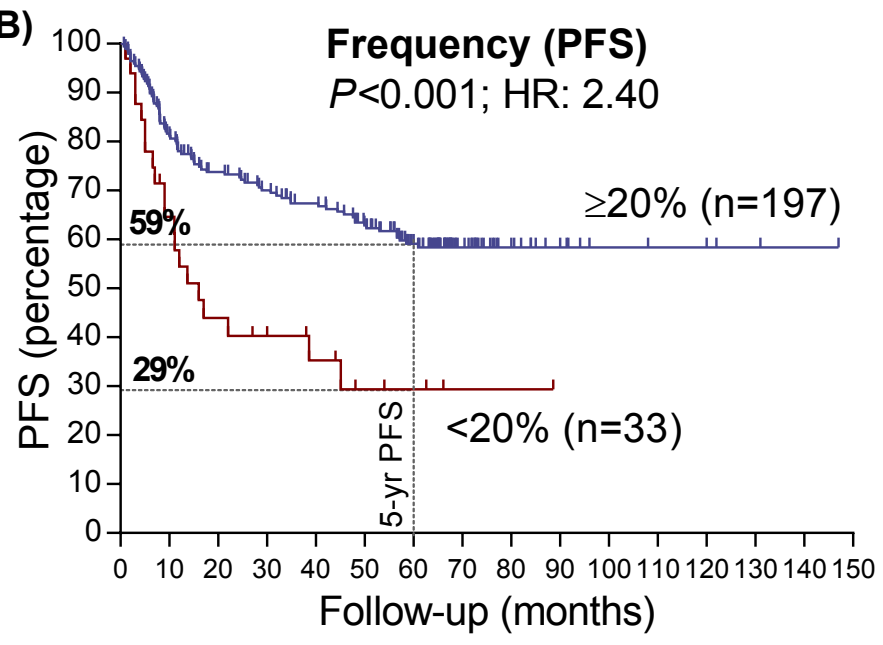

(D)

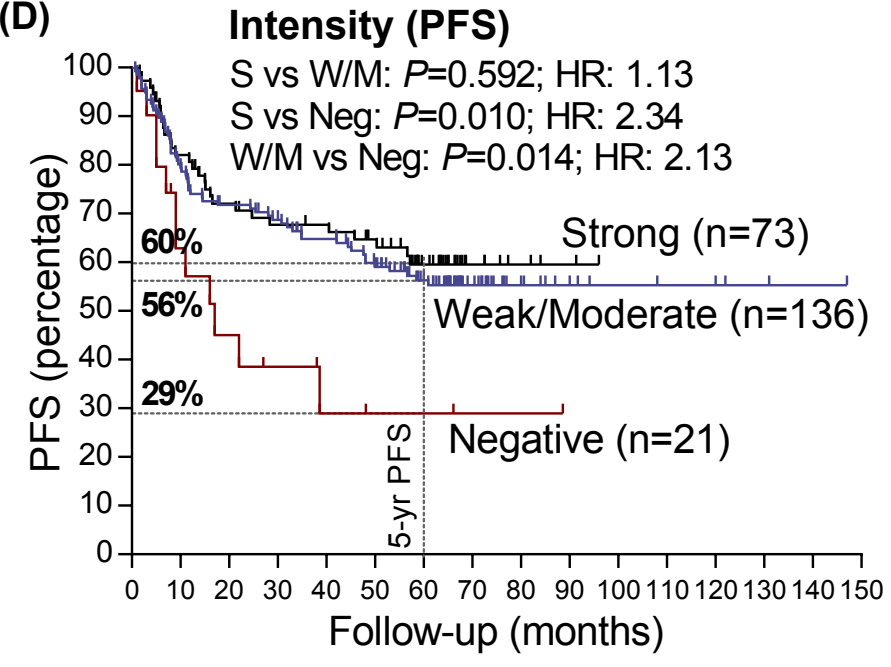


Fig. 4

(A)

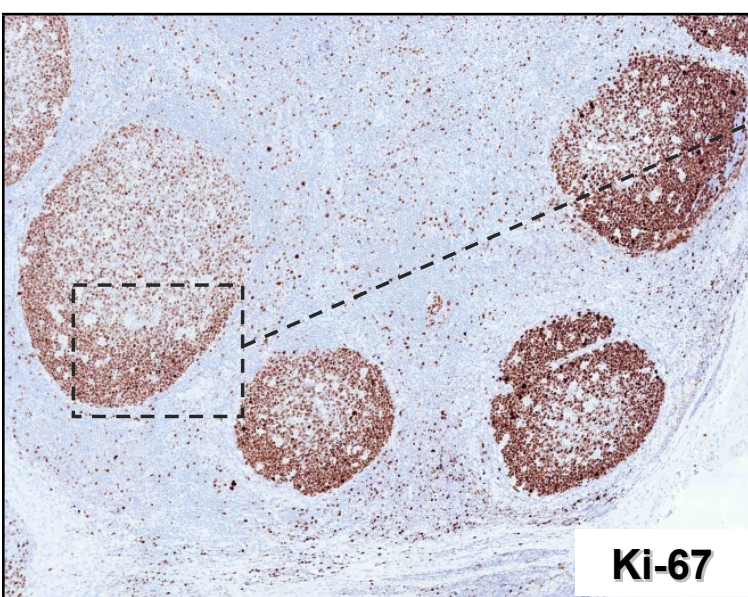

(B)

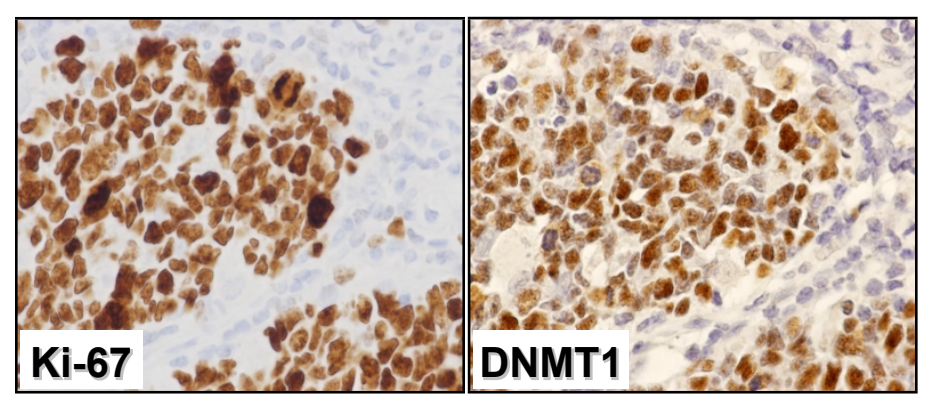

(D)

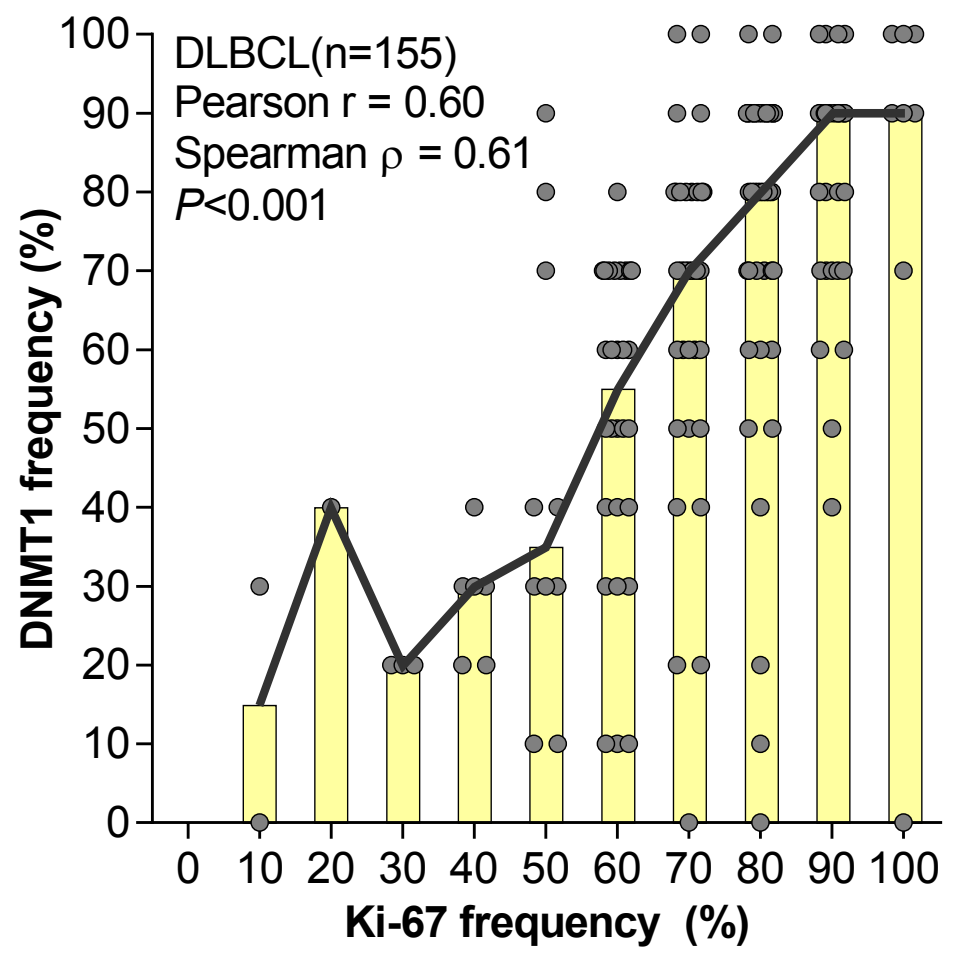

(C)

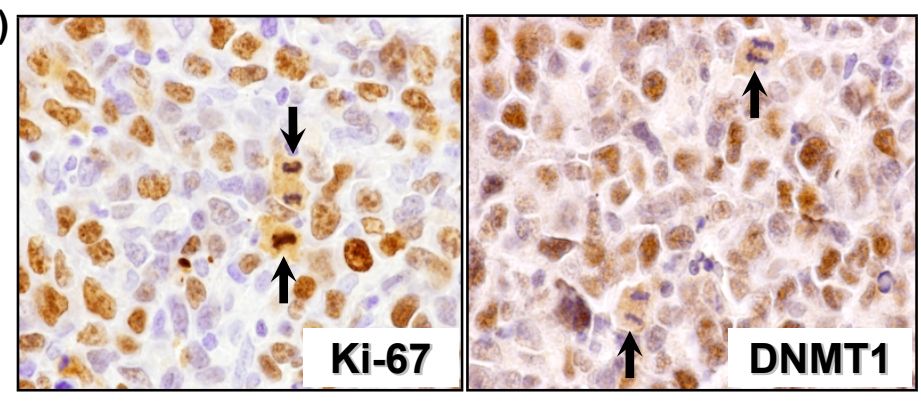

(E)

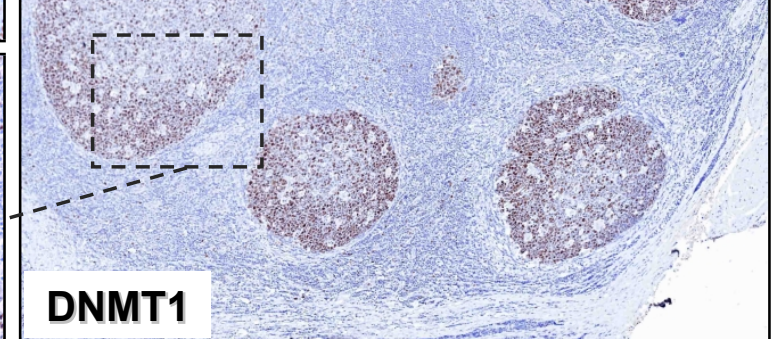


Supplementary Table 1: Antibodies and experimental parameters used for IHC. aa: amino acid.

\begin{tabular}{|c|c|c|c|c|c|c|c|}
\hline Protein & Supplier & $\begin{array}{l}\text { Host } \\
\text { (clone) }\end{array}$ & Isotype & $\begin{array}{l}\text { DNMT1 } \\
\text { immunogen }\end{array}$ & $\begin{array}{l}\text { Dilution } \\
\text { factor }\end{array}$ & $\begin{array}{l}\text { Antigen } \\
\text { retrieval } \\
\text { condition }\end{array}$ & $\begin{array}{l}\text { Incubation } \\
\text { duration } \\
\text { (minutes) }\end{array}$ \\
\hline DNMT1 & $\begin{array}{l}\text { Abcam } \\
\text { (Cambridge, } \\
\text { UK) }\end{array}$ & $\begin{array}{l}\text { Rabbit } \\
\text { (polyclonal) }\end{array}$ & $\lg G$ & $100-200$ aа & $1: 500$ & $\begin{array}{l}\text { Tris-EDTA, } \\
\text { pH } 9.0 \\
(10 \mathrm{~min})\end{array}$ & 30 \\
\hline DNMT1 & $\begin{array}{l}\text { Abcam } \\
\text { (Cambridge, } \\
\text { UK) }\end{array}$ & $\begin{array}{l}\text { Mouse } \\
\text { (2B5) }\end{array}$ & $\lg G 1$ & $1-111$ aa & $1: 200$ & $\begin{array}{l}\text { Tris-EDTA, } \\
\text { pH } 9.0 \\
\text { (10 min) }\end{array}$ & 30 \\
\hline DNMT1 & $\begin{array}{l}\text { Abcam } \\
\text { (Cambridge, } \\
\text { UK) }\end{array}$ & $\begin{array}{l}\text { Mouse } \\
(60 B 1220.1)\end{array}$ & $\operatorname{lgG} 1$ & $637-650$ aа & $1: 100$ & $\begin{array}{l}\text { Tris-EDTA, } \\
\text { pH } 9.0 \\
\text { (10 min) }\end{array}$ & 30 \\
\hline DNMT1 & $\begin{array}{l}\text { BD Biosciences } \\
\text { (San Jose, CA) }\end{array}$ & $\begin{array}{l}\text { Mouse } \\
\text { (18/DNMT1) }\end{array}$ & $\lg G 2 b$ & $476-670$ aа & $1: 20$ & $\begin{array}{l}\text { Tris-EDTA, } \\
\mathrm{pH} 9.0 \\
\text { (10 min) }\end{array}$ & 30 \\
\hline Ki-67 & $\begin{array}{l}\text { Dako (Glostrup, } \\
\text { Denmark) }\end{array}$ & $\begin{array}{l}\text { Mouse } \\
(\mathrm{MIB}-1)\end{array}$ & $\lg G 1$ & - & $1: 50$ & $\begin{array}{l}\text { Tris-EDTA, } \\
\mathrm{pH} 9.0 \\
\text { (3 min) }\end{array}$ & 30 \\
\hline
\end{tabular}




\section{Supplementary Fig. 1}

(A)

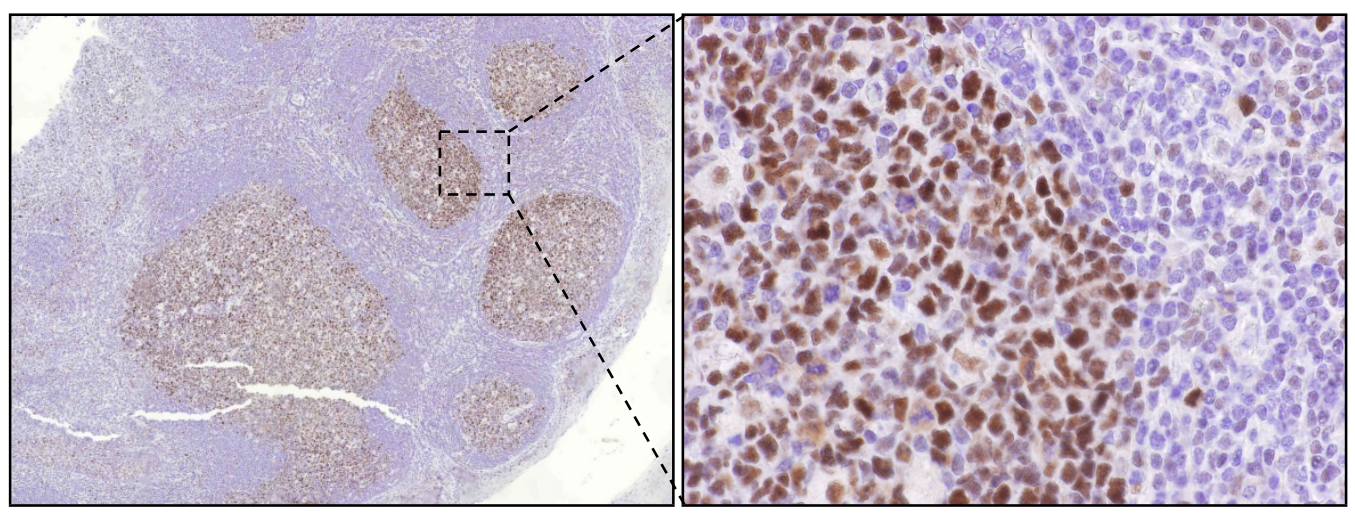

(B)

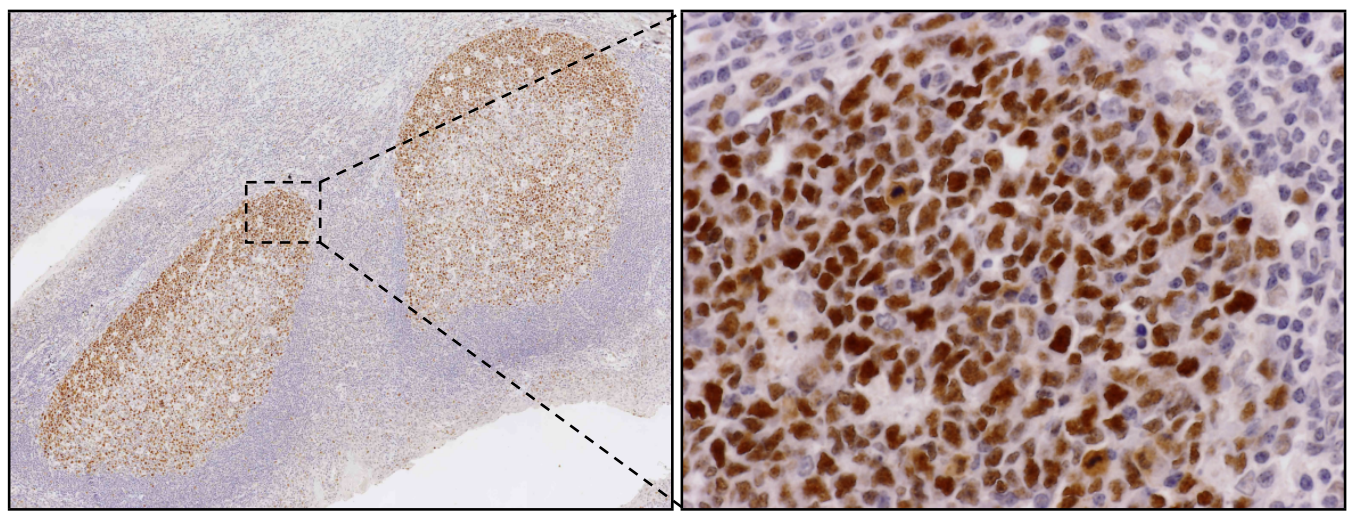

(C)

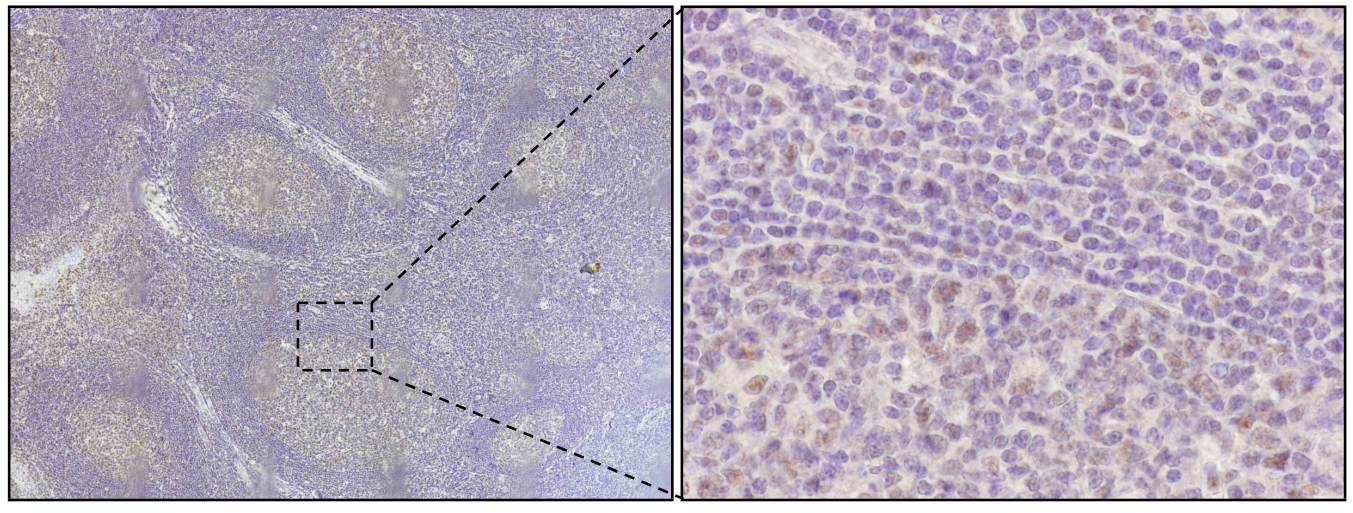

(D)

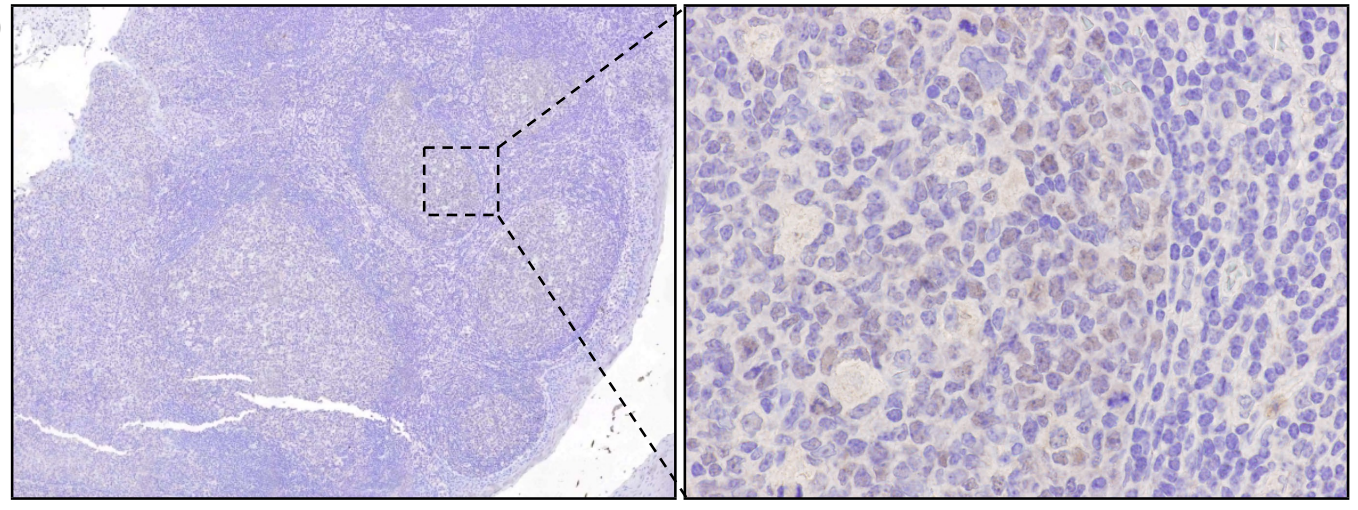


Supplementary Fig. 2

(A)

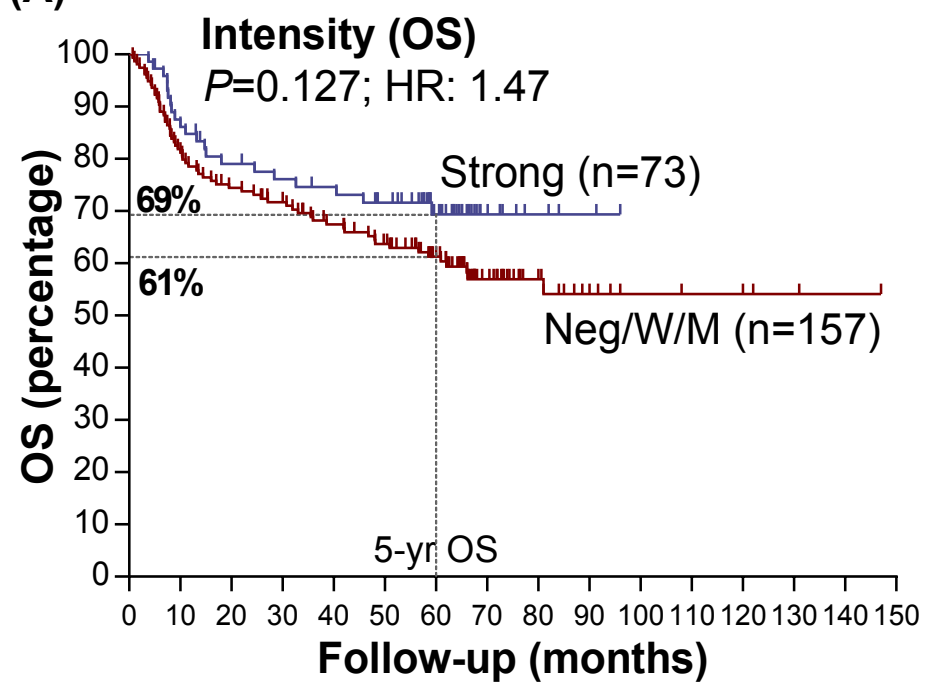

(C)

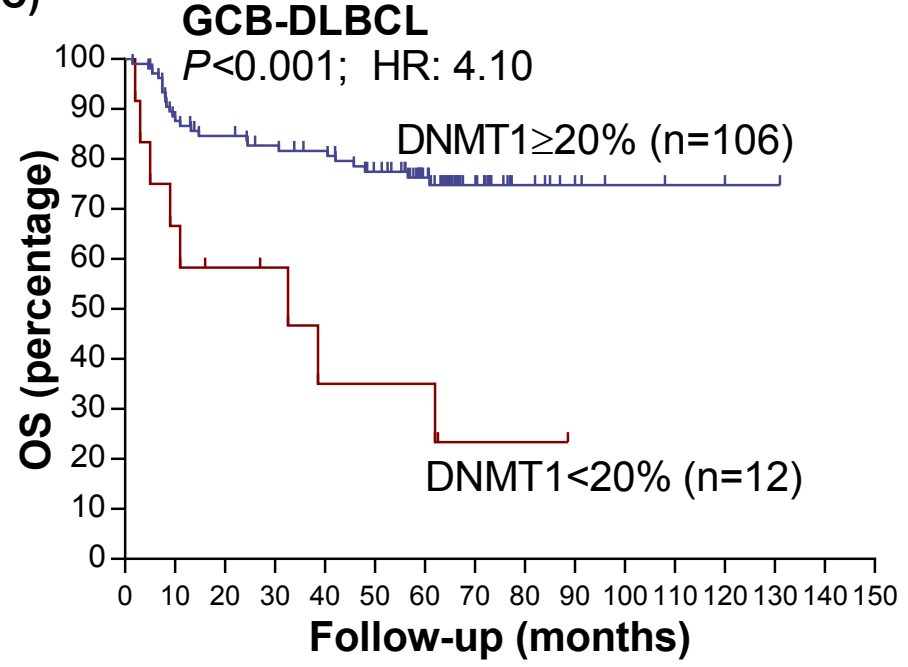

(E)

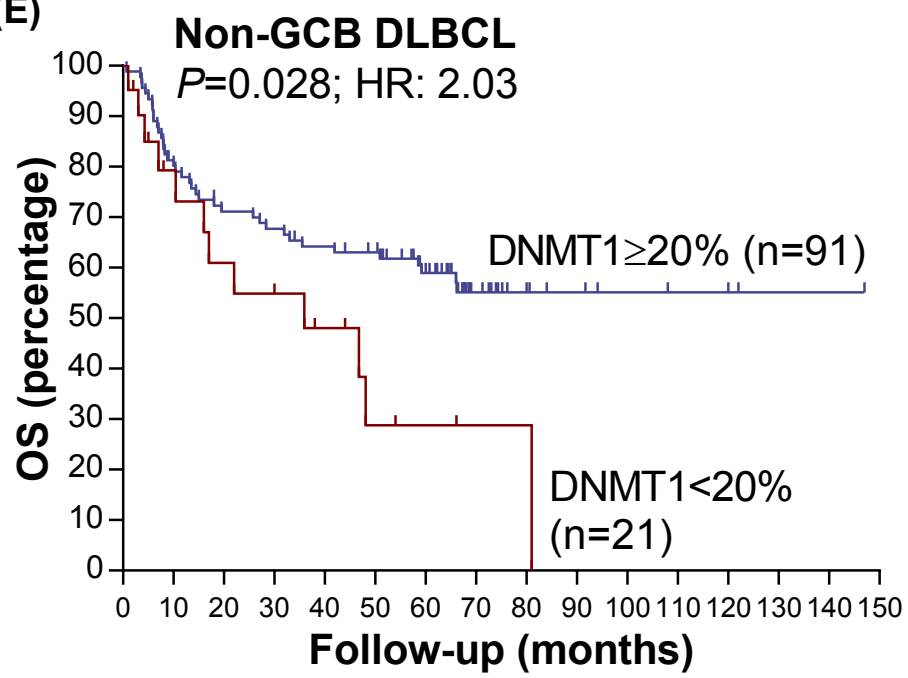

(B)

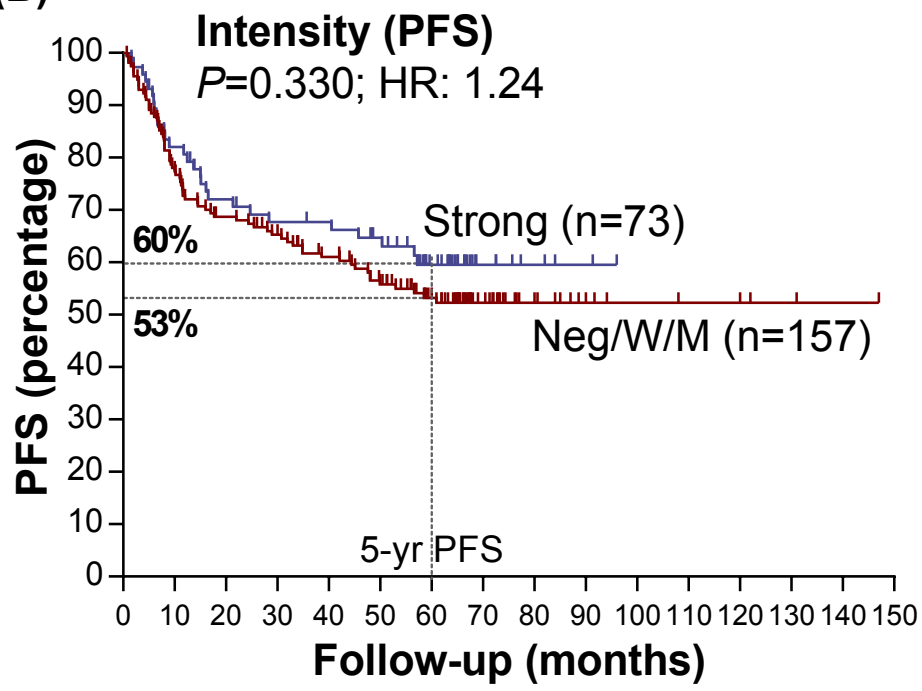

(D)

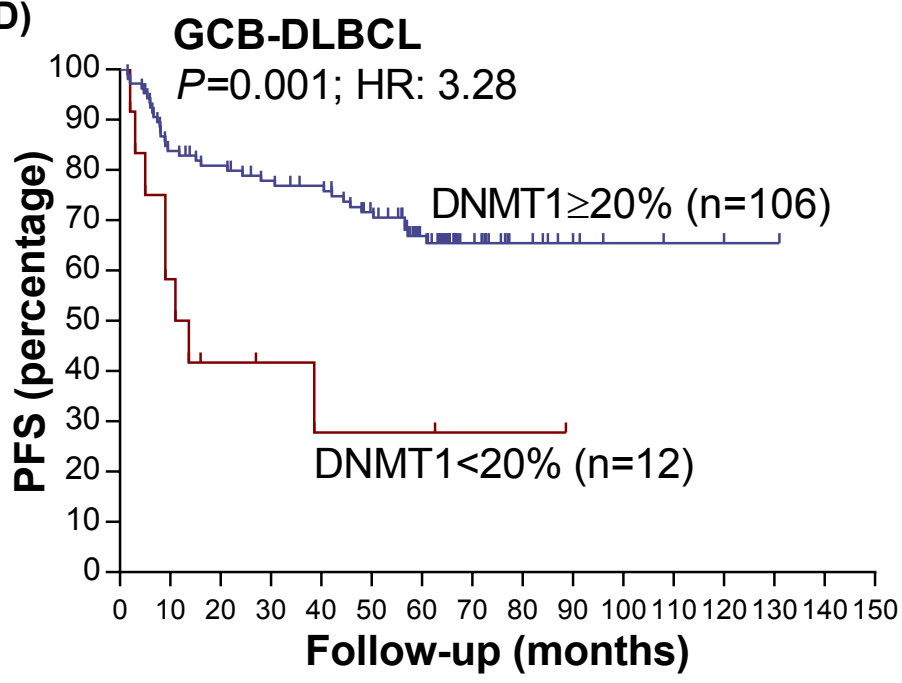

(F)

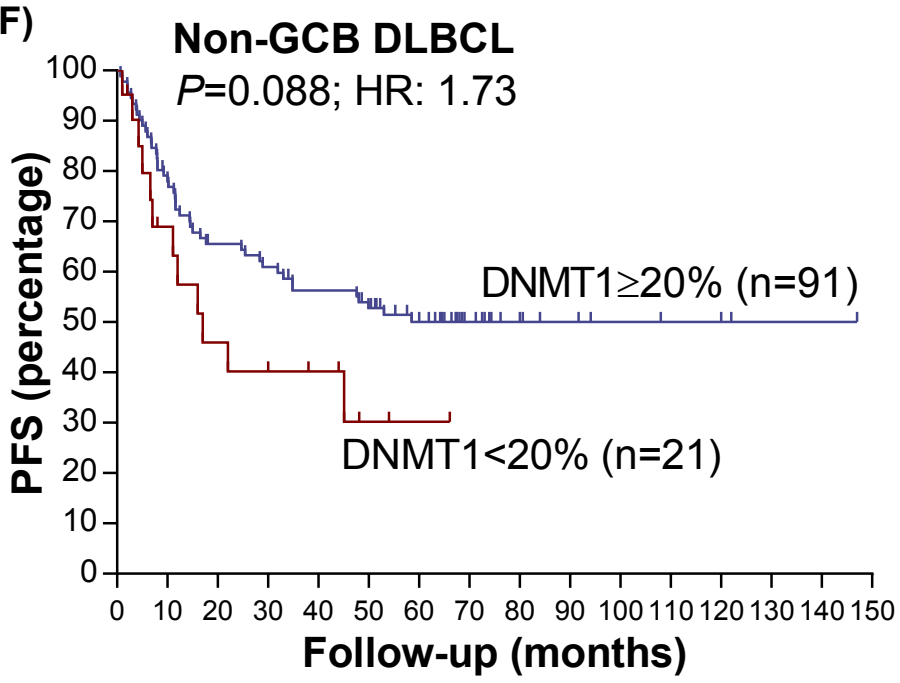


Supplementary Fig. 3
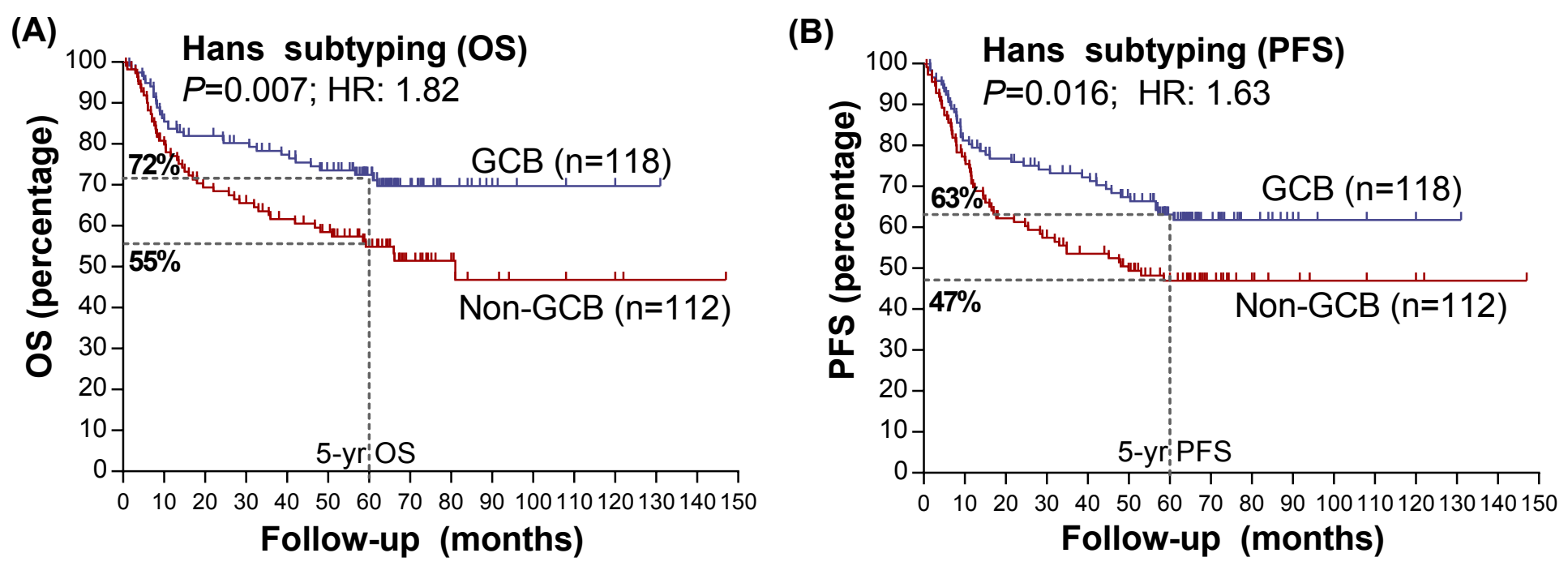

Follow-up (months)

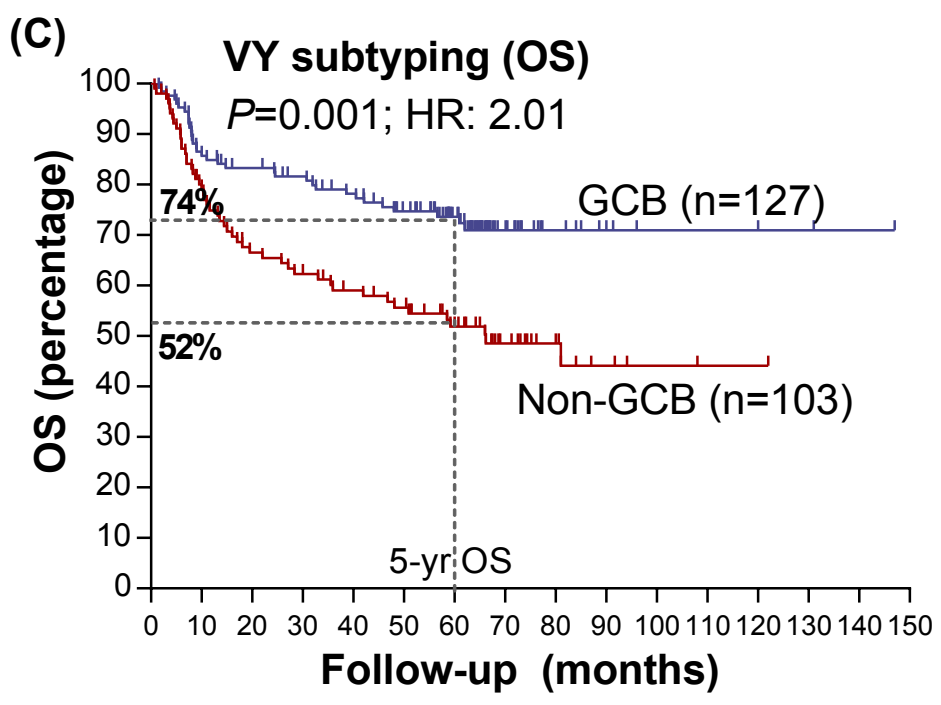

(D)

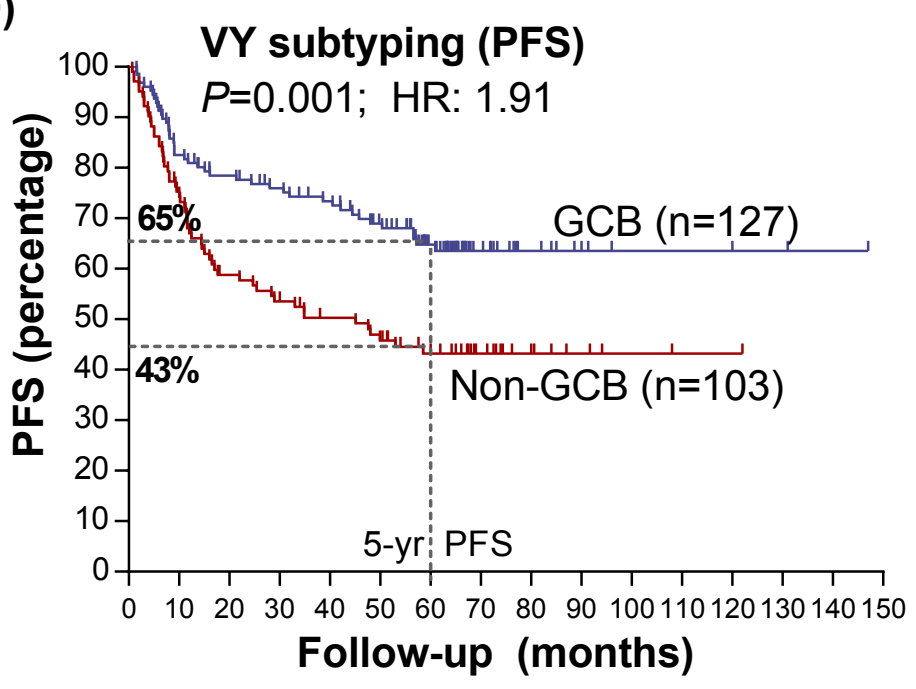


Supplementary Fig. 4

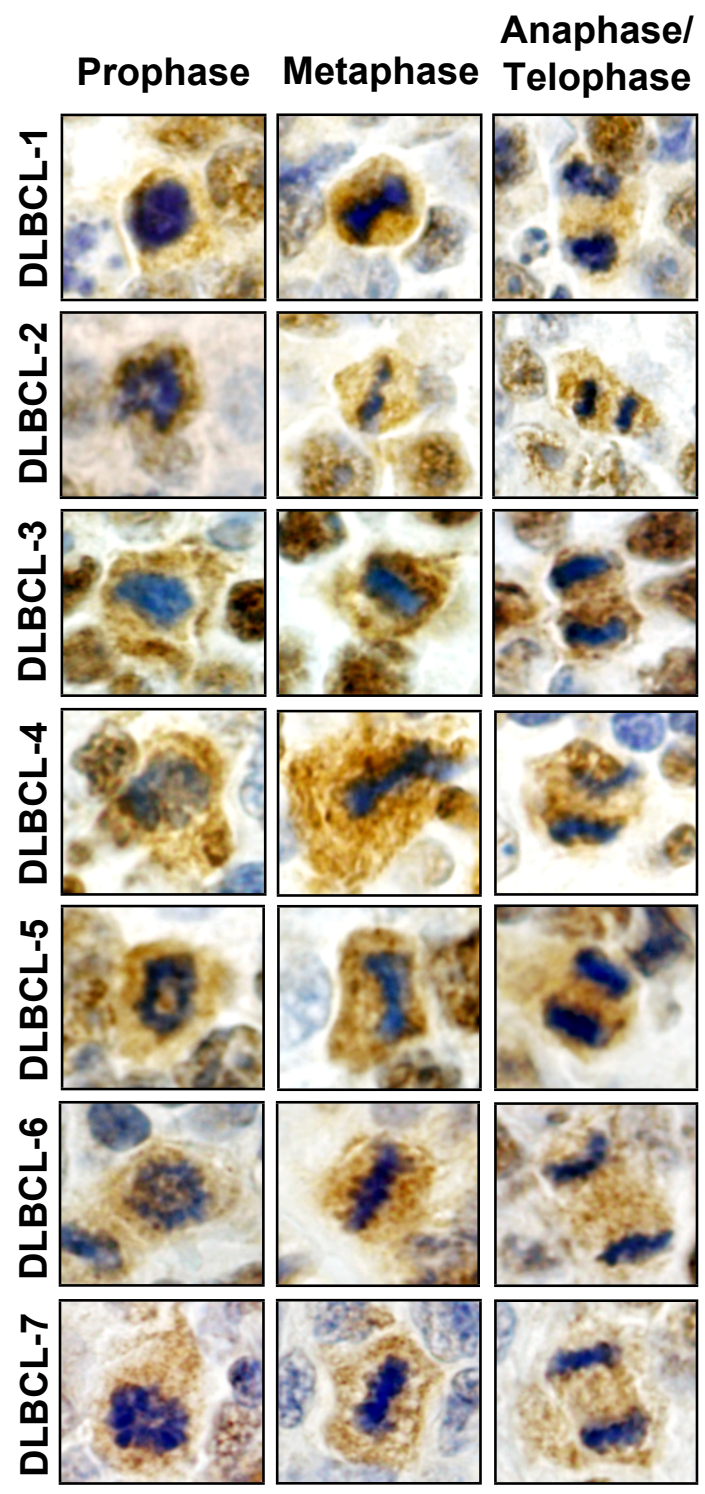

